Supporting Information

\title{
Photothermally Driven High-Speed Crystal Actuation and Its Simulation
}

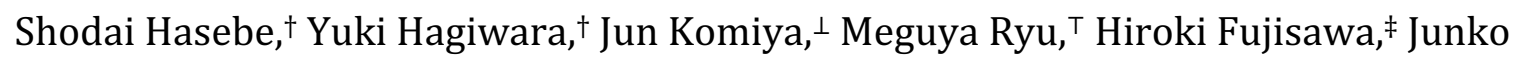

Morikawa,‡ Tetsuro Katayama,\# Daiki Yamanaka,\# Akihiro Furube,\# Hiroyasu Sato," Toru

Asahi, ${ }^{\dagger}, \perp, \S$ and Hideko Koshima*,§

†Department of Advanced Science and Engineering, Graduate School of Advanced Science and Engineering, Waseda University, 3-4-1 Okubo, Shinjuku-ku, Tokyo 169-8555, Japan

${ }^{\perp}$ Department of Nanoscience and Nanoengineering, Graduate School of Advanced Science and Engineering, Waseda University, 3-4-1 Okubo, Shinjuku-ku, Tokyo 169-8555, Japan

'Tesearch Institute for Material and Chemical Measurement, National Metrology Institute of Japan (AIST), Tsukuba Central 3, 1-1-1 Umezono, Tsukuba 305-8563, Japan

${ }^{\ddagger}$ School of Materials and Chemical Technology, Tokyo Institute of Technology, Ookayama, Meguro-ku, Tokyo 1528550, Japan

\#Department of Optical Science, Tokushima University, 2-1 Minamisanjyojima-cho, Tokushima-shi 770-8506, Japan "Rigaku Corporation, 3-9-12 Matasubara-cho, Akishima-shi, Tokyo 196-8666, Japan

${ }^{\S}$ Research Organization for Nano and Life Innovation, Waseda University, 513 Wasedatsurumaki-cho, Shinjuku-ku, Tokyo 162-0041, Japan

\footnotetext{
* Correspondence to h.koshima@kurenai.waseda.jp
} 


\section{CONTENTS}

1. Crystal structures

$\begin{array}{ll}\text { Tables S1, S2, Figures S1, S2 } & \text { S3 }\end{array}$

2. Spectroscopy

Figures S3-S7, Table S3

3. Crystal bending by photoisomerization

Figures S8-S11, Tables S4, S5

4. Estimation of photoreacted layer thickness by Timoshenko's bimetal model Figure S12

5. Crystal bending by the photothermal effect

Figures S13-S17

6. Estimation of photothermal energy generated inside crystal

Figures S18-S20

7. Measurement of thermal diffusivity of the enol-1 crystal by TWA method Figures S21-S23

8. Simulation I of photothermally driven bending by using measured top surface temperature

Figure S24

9. Simulation II of photothermally driven bending based on the estimated photothermal energy

Figures S25, S26

10. List of movies

Movies S1-S4

11. References 


\section{Crystal structures}

Table S1. Crystallographic constants of the enol-1 crystal depending on temperature.

\begin{tabular}{llllll}
\hline Temperature $\left({ }^{\circ} \mathrm{C}\right)$ & -100 & -40 & 20 & 50 & 80 \\
\hline Crystal system & Monoclinic & Monoclinic & Monoclinic & Monoclinic & Monoclinic \\
Space group & $P 2_{1}$ & $P{ }_{1}$ & $P 2_{1}$ & $P{ }_{1}$ & $P 2_{1}$ \\
$a(\AA)$ & $10.8292(2)$ & $10.8658(3)$ & $10.9026(4)$ & $10.9165(4)$ & $10.9302(6)$ \\
$b(\AA)$ & $6.1481(10)$ & $6.1932(2)$ & $6.2385(2)$ & $6.2613(2)$ & $6.2869(3)$ \\
$c(\AA)$ & $14.9928(3)$ & $15.0176(5)$ & $15.0924(7)$ & $15.1369(6)$ & $15.1994(11)$ \\
$\beta\left({ }^{\circ}\right)$ & $109.004(2)$ & $109.001(4)$ & $108.980(5)$ & $108.934(4)$ & $108.909(7)$ \\
$V\left(\AA^{3}\right)$ & $943.80(3)$ & $955.53(6)$ & $970.71(7)$ & $978.65(7)$ & $988.09(11)$ \\
$Z$ & 2 & 2 & 2 & 2 & 2 \\
$\rho_{\text {calc }}\left(\mathrm{g} \cdot \mathrm{cm}{ }^{-3}\right)$ & 1.142 & 1.128 & 1.110 & 1.101 & 1.091 \\
$R_{I}[I>2 \sigma(I)]$ & 0.0417 & 0.0430 & 0.0698 & 0.0488 & 0.0675 \\
$w R_{2}[I>2 \sigma(I)]$ & 0.1148 & 0.1231 & 0.2162 & 0.1530 & 0.1934 \\
$G O F$ & 1.053 & 1.071 & 1.074 & 1.061 & 1.004 \\
\hline
\end{tabular}


Table S2. Distances, angles, and occupancies depending on temperature.

\begin{tabular}{llllll}
\hline Temperature $\left({ }^{\circ} \mathrm{C}\right)$ & -100 & -40 & +20 & +50 & +80 \\
\hline $\mathrm{N}=\mathrm{C}$ bond length $(\AA)$ & 1.291 & 1.289 & 1.291 & 1.287 & 1.275 \\
$\mathrm{C}-\mathrm{O}$ bond distance $(\AA)$ & 1.358 & 1.357 & 1.363 & 1.355 & 1.348 \\
$\begin{array}{l}\text { Intramolecular hydrogen bond } \\
\text { distance }(\mathrm{O}---\mathrm{N})(\AA)\end{array}$ & 2.611 & 2.614 & 2.606 & 2.615 & 2.612 \\
$\begin{array}{l}\text { Intramolecular hydrogen bond } \\
\text { distance }(\mathrm{O}-\mathrm{H}---\mathrm{N})(\AA)\end{array}$ & 1.872 & 1.874 & 1.867 & 1.874 & 1.876 \\
$\begin{array}{l}\text { Intramolecular hydrogen bond } \\
\text { angle }(\mathrm{O}-\mathrm{H}---\mathrm{N})\left({ }^{\circ}\right)\end{array}$ & 149.46 & 149.45 & 149.39 & 149.53 & 148.77 \\
$\begin{array}{l}\text { Intermolecular hydrogen bond } \\
\text { distance }(\mathrm{N}---\mathrm{O})(\AA)\end{array}$ & 3.232 & 3.279 & 3.331 & 3.358 & 3.396 \\
$\begin{array}{l}\text { Intermolecular hydrogen bond } \\
\text { distance }(\mathrm{N}-\mathrm{H}---\mathrm{O})(\AA)\end{array}$ & 2.558 & 2.483 & 2.634 & 2.696 & 2.748 \\
$\begin{array}{l}\text { Intermolecular hydrogen bond } \\
\text { angle }(\mathrm{N}-\mathrm{H}---\mathrm{O})\left({ }^{\circ}\right)\end{array}$ & 135.83 & 137.86 & 138.74 & 134.5 & 133.03 \\
$\begin{array}{l}\text { Dihedral angle between phenyl } \\
\text { and salicyl planes }\left({ }^{\circ}\right)\end{array}$ & 34.98 & 35.09 & 34.96 & 35.03 & 35.30 \\
$\begin{array}{l}\text { Occupancy of disordered tert- } \\
\text { butyl group }(\%)\end{array}$ & $100: 0$ & $100: 0$ & $90.1: 9.9$ & $83.3: 16.7$ & $80.6: 19.4$ \\
\hline
\end{tabular}



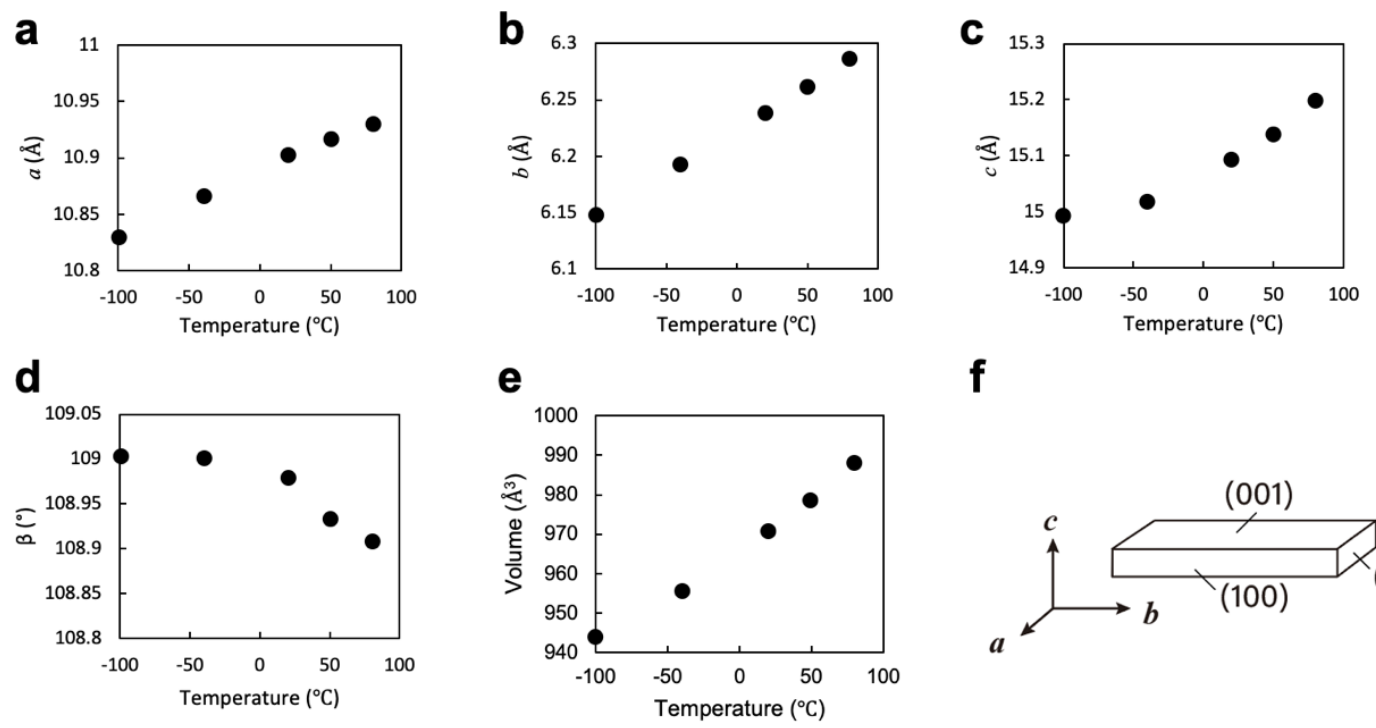

$\mathbf{f}$

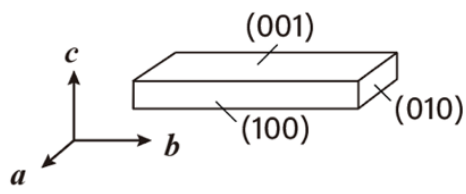

\section{g}

h

i
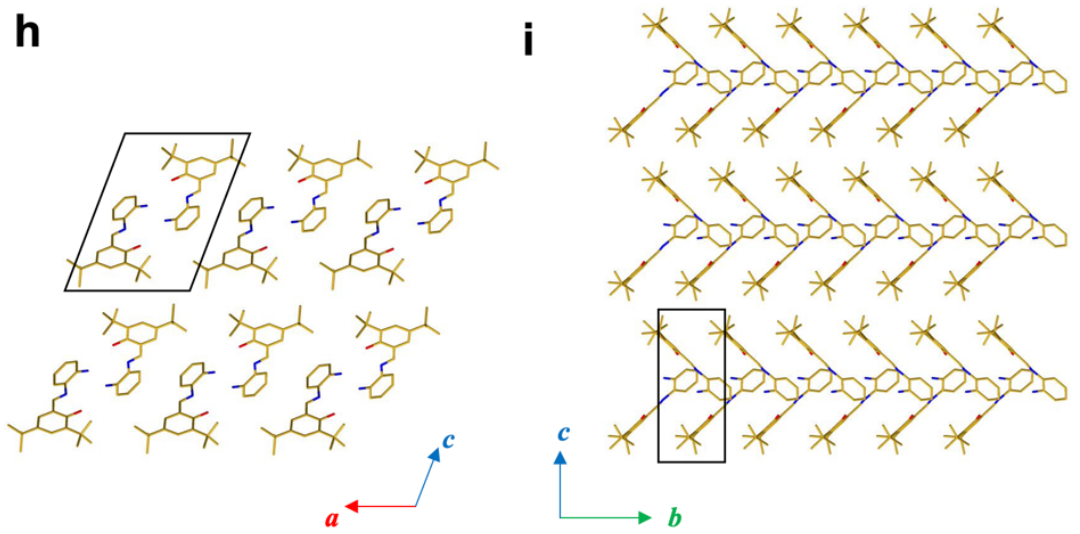

Figure S1. Temperature dependence of (a) $a$-, (b) $b$-, and (c) $c$-axes, (d) $\beta$-angle, and (e) volume of the unit cell. (f) Face indices of the plate-like crystal. Packing diagram on the (g) (001), (h) (010), and (i) (100) faces. Disordered tert-butyl substituents with minor occupancies and hydrogen atoms are omitted for clarity. 
a

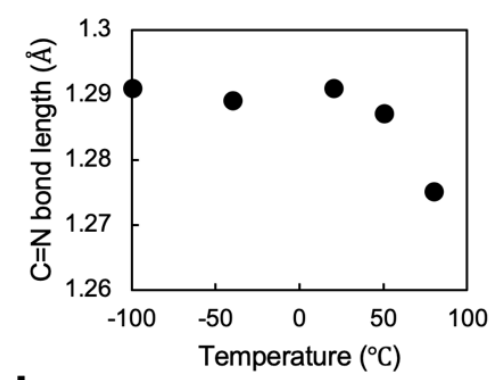

d

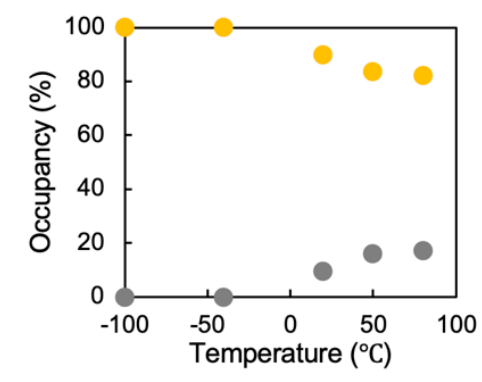

b

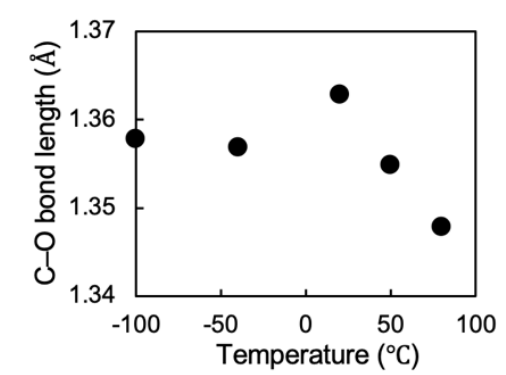

e

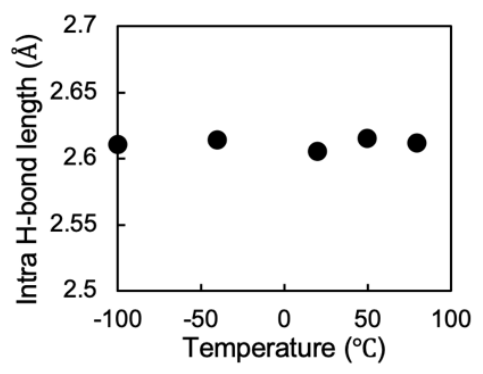

C

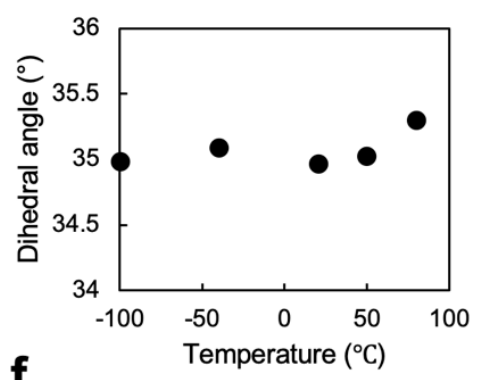

$\mathbf{f}$

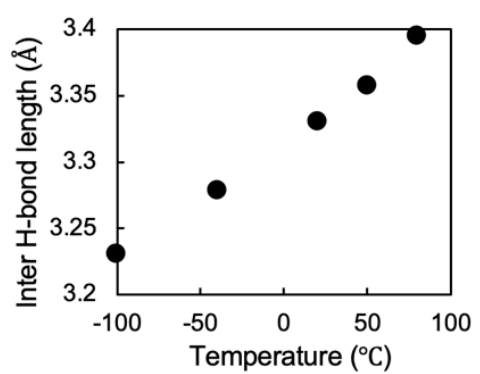

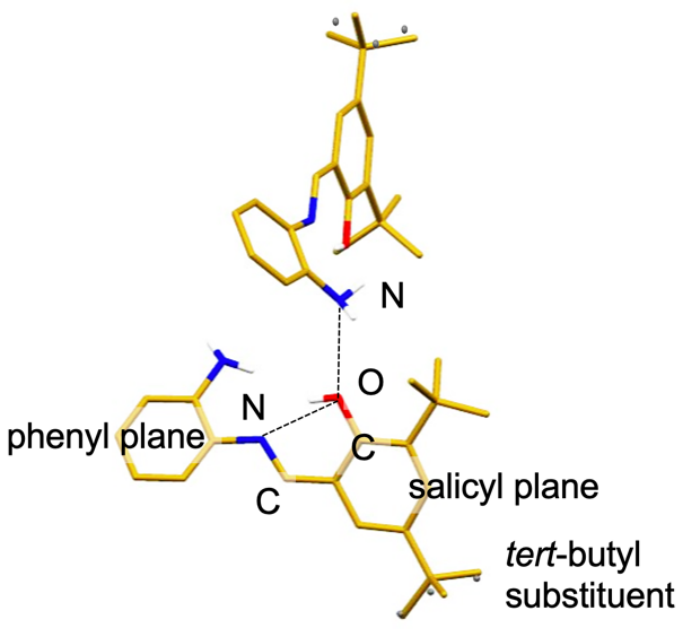

Figure S2. Temperature dependence of (a) $\mathrm{C}=\mathrm{N}$ bond distance of the Schiff base, (b) $\mathrm{C}-\mathrm{O}$ bond distance of the salicyl group, (c) dihedral angle between the salicyl and phenyl planes, (d), occupancy of the disordered tert-butyl substituent, (e) intramolecular hydrogen bond distance (N--$\mathrm{O})$ and (f) intermolecular hydrogen bond distance (N---O). 


\section{Spectroscopy}
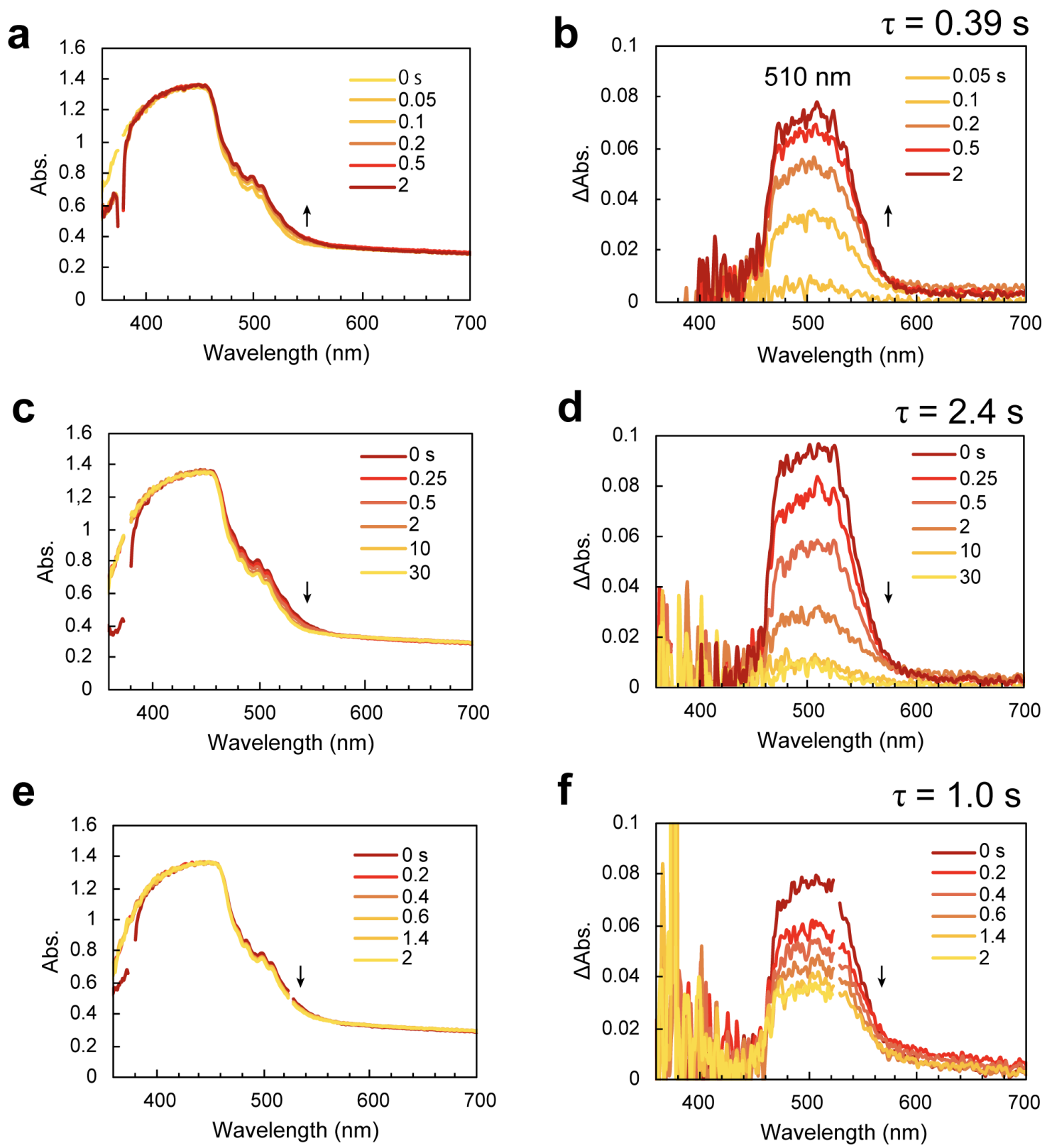

Figure S3. Photoisomerization properties of the enol-1 crystal. (a, c, e) UV-vis absorption spectra and (b, d, f) difference spectra of an enol-1 single crystal before and after UV light $(375 \mathrm{~nm}, 90 \mathrm{~mW}$ $\mathrm{cm}^{-2}$ ) irradiation at $20{ }^{\circ} \mathrm{C}$; (a, b) Photoisomerization under UV light irradiation, (c, d) thermal backisomerization after stopping UV light exposure for 60 seconds, (e, f) photochemical backisomerization by visible light $\left(520 \mathrm{~nm}, 62 \mathrm{~mW} \mathrm{~cm}^{-2}\right)$ illumination after UV light exposure for 60 seconds. 


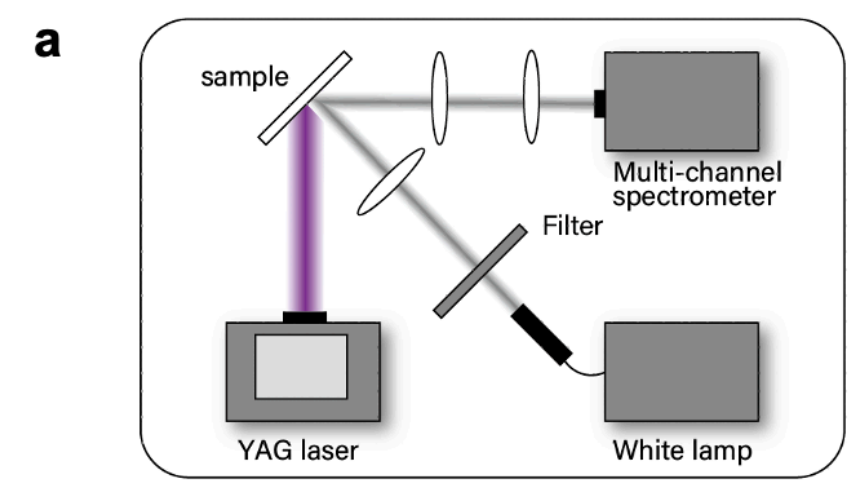

b

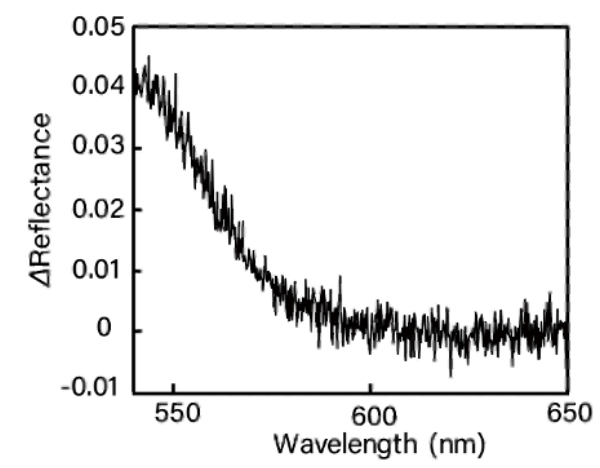

C $\quad \times 10^{-4}$

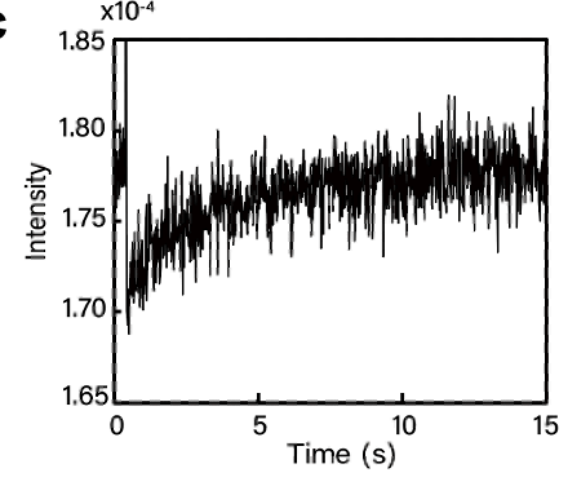

Figure S4. (a) Experimental setup for measurement of transient diffuse reflectance spectrum of the enol-1 powdered crystals; excitation, $10 \mathrm{~ns}, 355 \mathrm{~nm}, 6-10 \mathrm{~mJ} /$ pulse, $3 \times 3 \mathrm{~mm}^{2}$. (b) Transient diffuse reflectance spectrum of the powdered crystals, and (c) the decay curve at $550 \mathrm{~nm}$. The time constant of the thermal back-isomerization was calculated from the decay curve to be $3.6 \mathrm{~s}$.

A halogen lamp (SCHOTT, KL1500LCD; 150W) was used for the probe light source, and a Nd:YAG laser (Continuum, Minilite; $355 \mathrm{~nm}$ wavelength, 6-10 $\mathrm{mJ} /$ pulse, $10 \mathrm{~ns}$ pulse duration) was employed for the pump light source. A single shot from the pump laser was applied onto the power sample $(3 \times$ $3 \mathrm{~mm}^{2}$ area) to observe the nonreversible reaction using a multichannel photodetector (Ocean Optics, USB4000) that monitors the diffuse reflected light from the sample with the accumulation time of 10-20 ms. The obtained spectra were analyzed to calculate the reflectance change spectra and temporal responses at a specific wavelength. 


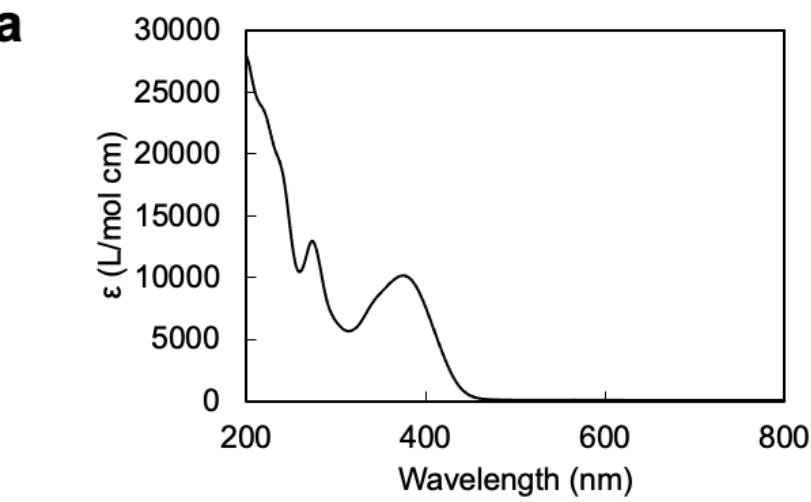

b

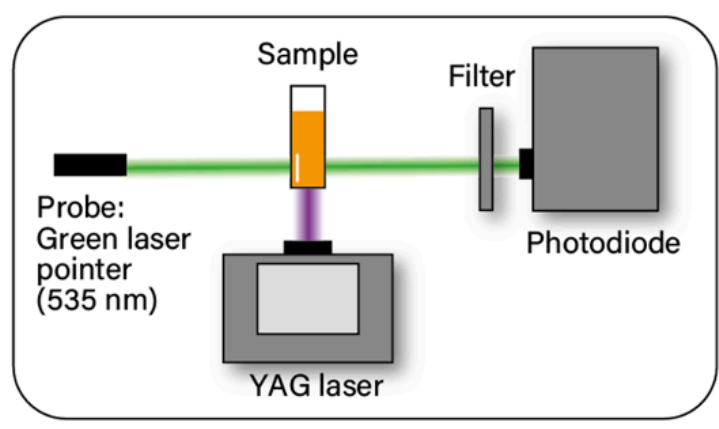

C

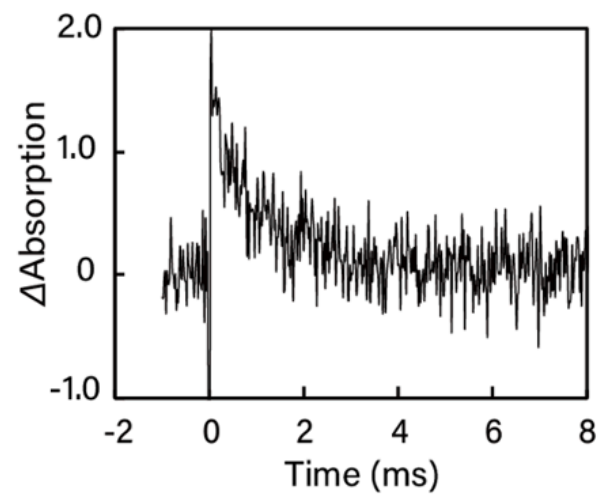

Figure S5. (a) UV-vis absorption spectrum of enol-1 in acetonitrile at room temperature. (b) Experimental setup for measurement of the transient absorption of enol-1 in acetonitrile; excitation $10 \mathrm{~ns}, 355 \mathrm{~nm}, 10 \mathrm{~Hz}, 6-10 \mathrm{~mJ} /$ pulse, $3 \times 3 \mathrm{~mm}^{2}$, and (c) the decay curve at $535 \mathrm{~nm}$. The time constant of the thermal back-isomerization was calculated from the decay curve to be $9.7 \times 10^{-4} \mathrm{~s}$ (0.97 ms). 
Table S3. Time constants of isomerization of molecules, time to bend/straighten of photomechanical crystals.

\begin{tabular}{|c|c|c|c|c|c|c|c|c|c|c|}
\hline \multirow[t]{2}{*}{ Compound } & \multirow[t]{2}{*}{ No. } & \multicolumn{3}{|c|}{$\begin{array}{l}\text { Time constants of } \\
\text { isomerization of molecules }\end{array}$} & \multicolumn{3}{|c|}{$\begin{array}{l}\text { Time to bend/straighten of } \\
\text { crystals (s) }\end{array}$} & \multirow[t]{2}{*}{$\begin{array}{l}\text { Bend } \\
\text { angle }\left({ }^{\circ}\right)\end{array}$} & \multirow[t]{2}{*}{ Size $\left(\mu \mathrm{m}^{3}\right)$} & \multirow[t]{2}{*}{ Reference } \\
\hline & & UV & $\Delta$ & Vis & UV & $\Delta$ & Vis & & & \\
\hline Salicylidene- & 1 & 0.39 & 2.4 & 1.0 & 1.2 & 5.7 & 2.3 & 20.3 & $1170 \times 14.5 \times 10.2$ & This work \\
\hline \multirow[t]{4}{*}{ aniline } & 1 & 0.39 & 2.4 & 1.0 & 0.05 & 0.05 & - & 0.31 & $1520 \times 72 \times 48.3$ & This work \\
\hline & $2(S)$ & 1.3 & 143 & 7.7 & 3.0 & 40 & 15 & 9.4 & $1412 \times 32 \times 12$ & 1 \\
\hline & 2 (rac) & 2.0 & 143 & 4.8 & 5.0 & 40 & 5.0 & 6.0 & $449 \times 12.3 \times 6.0$ & 1 \\
\hline & 3 & 2.6 & $\begin{array}{l}3.63 \\
(42\end{array}$ & 63 & 30 & 1400 & 4.3 & 25 & $50 \times 6.3 \times 2.1$ & 2 \\
\hline \multirow[t]{3}{*}{ Azobenzene } & 4 & - & - & - & 0.5 & 30 & - & $\sim 180$ & $525 \times 280 \times 5.0$ & 3 \\
\hline & 5 & - & - & - & 0.5 & 240 & 60 & 34 & $200 \times 25 \times 1.2$ & 4 \\
\hline & 6 & 0.55 & 12.4 & 1.14 & 6.0 & 180 & 120 & 5.5 & $238 \times 5.0 \times 3.0$ & 5 \\
\hline Fulgide & 7 & $\sim 1$ & - & $\sim 80$ & 2.0 & - & 30 & 9.0 & $109 \times 6.0 \times 2.0$ & 6 \\
\hline Anthracene & 8 & $\sim 300$ & $\begin{array}{l}>4.3 \\
(5 \mathrm{~d} c\end{array}$ & & 1200 & $\begin{array}{l}1.04 \times \\
(12 \mathrm{~d} a\end{array}$ & & 14 & $2700 \times 67 \times 15$ & 7 \\
\hline
\end{tabular}
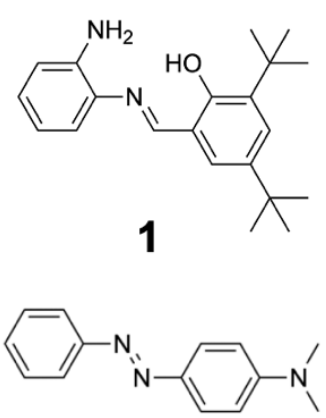

4<smiles>CC(C)=C1C(=O)OC(=O)C1=C(C)c1cc(C)oc1C</smiles>

7

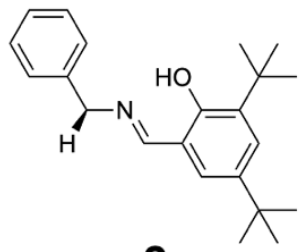

2

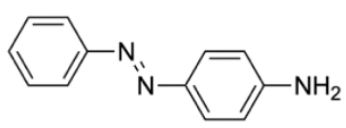

5<smiles>O=C(C=Cc1c2ccccc2cc2ccccc12)c1ccccc1</smiles>

8
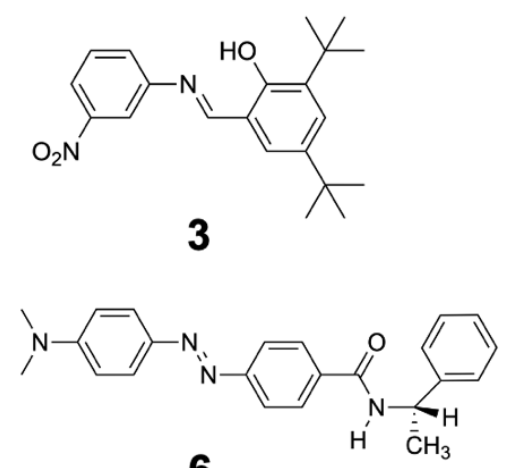

6 


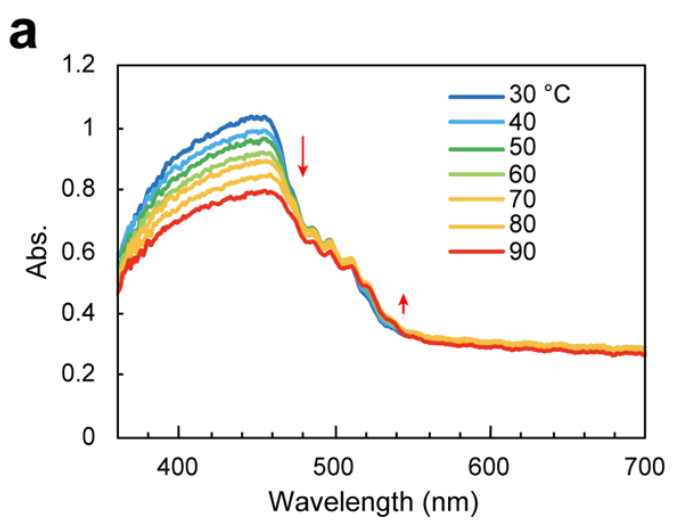

C

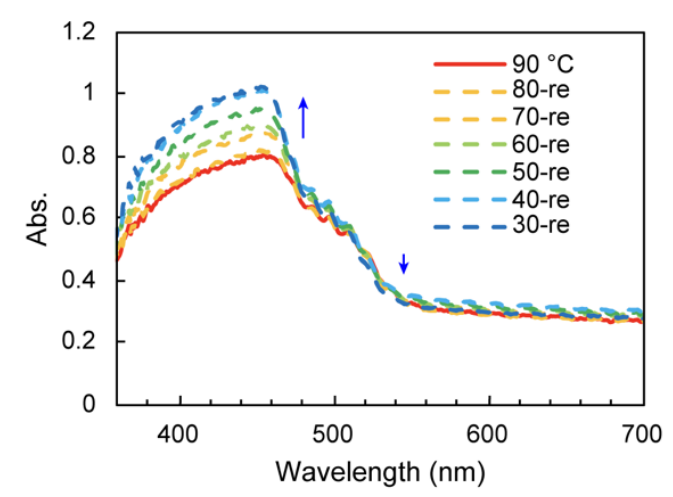

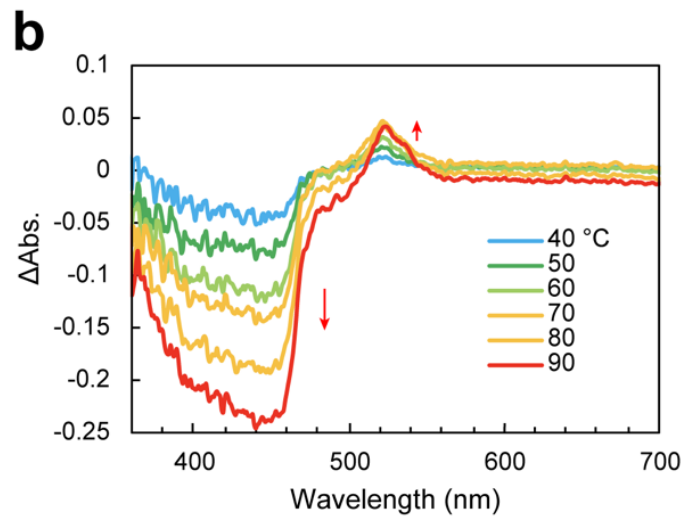

d

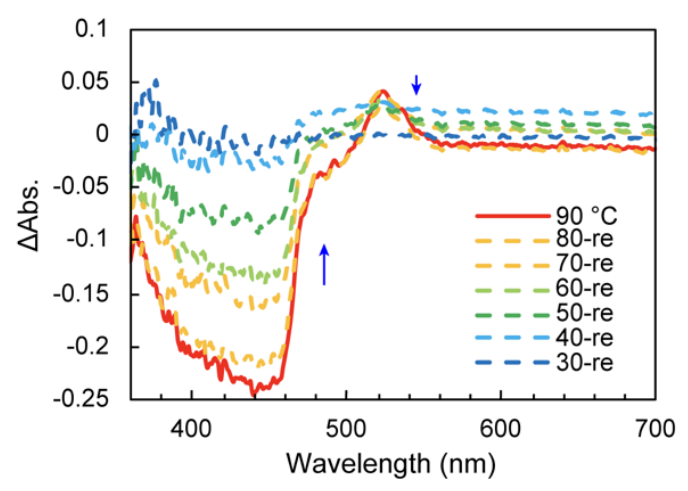

Figure S6. Thermal isomerization properties of the enol-1 crystal. Temperature dependence of (a, c) UV-vis absorption spectra and (b, d) difference spectra of a thin plate-like crystal on the (001) face on (a, b) heating from $30{ }^{\circ} \mathrm{C}$ to $90{ }^{\circ} \mathrm{C}$ and $(\mathrm{c}, \mathrm{d})$ cooling from $90{ }^{\circ} \mathrm{C}$ to $30{ }^{\circ} \mathrm{C}$. 


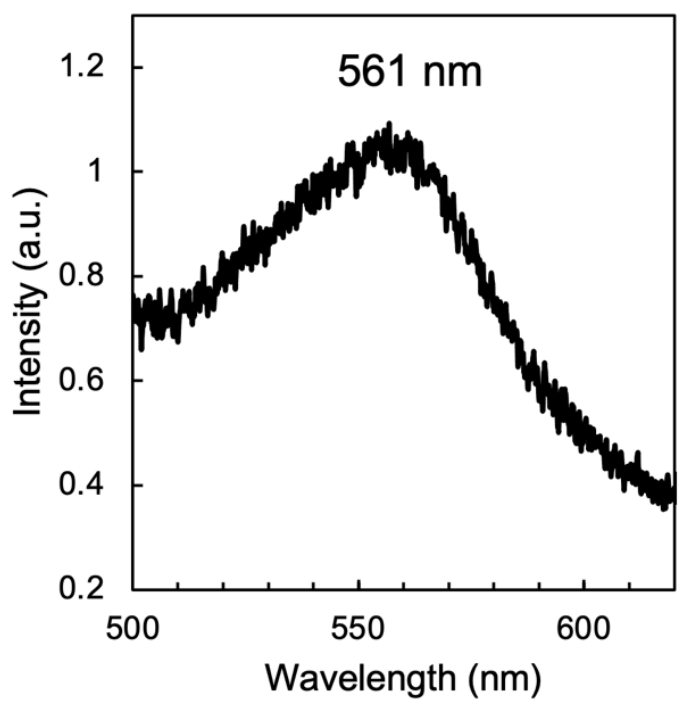

Figure S7. Steady-state fluorescence spectrum for enol-1 in the powdered crystal upon UV (365 $\mathrm{nm}$ ) irradiation with a maximum at $561 \mathrm{~nm}$. 


\section{Crystal bending by photoisomerization}
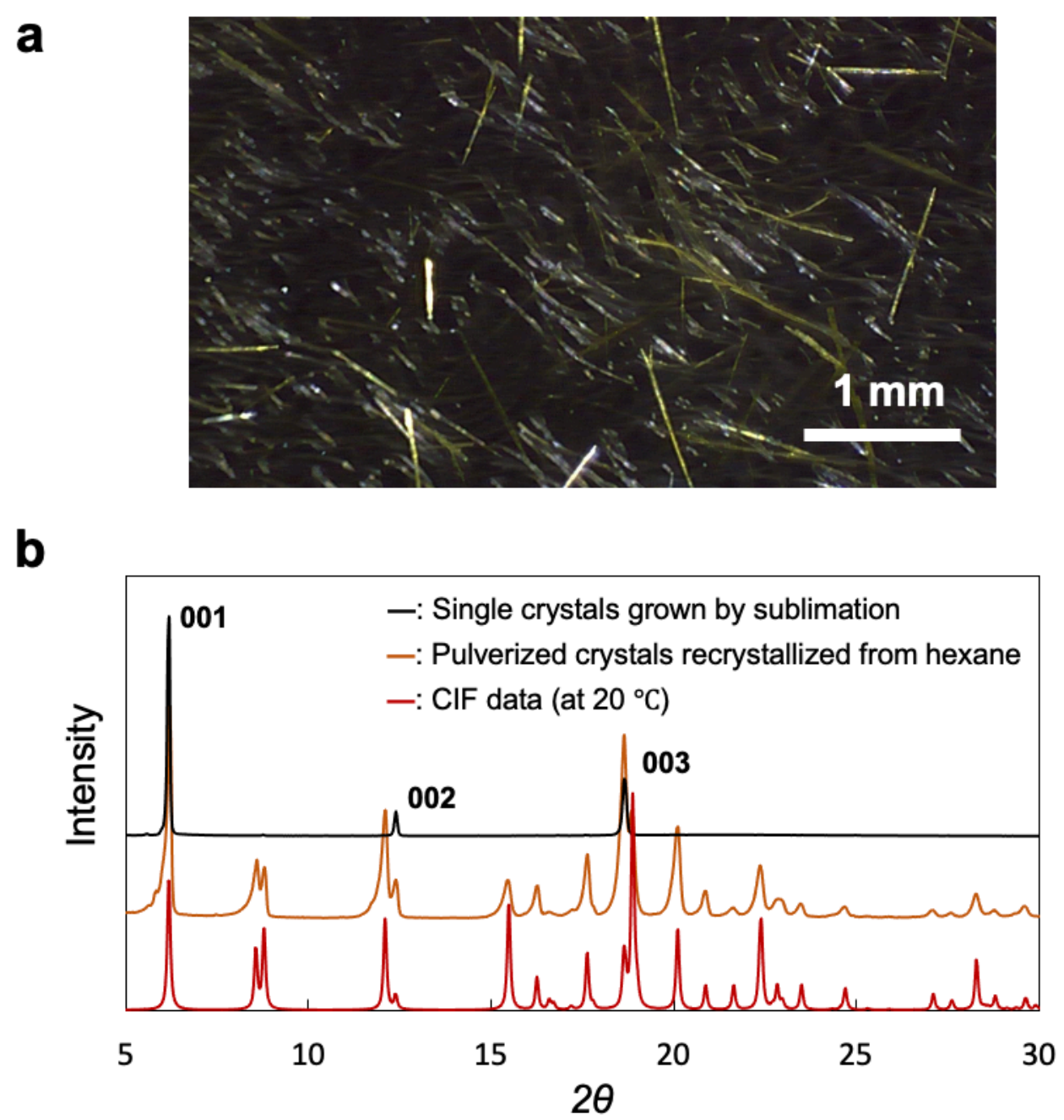

Figure S8. (a) Plate-like microcrystals of enol-1 prepared by sublimation on the glass plate. The scale bar is $1 \mathrm{~mm}$. (b) Powder X-ray diffraction (XRD) profiles of the enol-1 crystals.

Microcrystals of enol-1 were prepared by sublimation of bulk crystals in a small pan covered with a glass plate about $10{ }^{\circ} \mathrm{C}$ below the melting point (136.1-137.9 $\left.{ }^{\circ} \mathrm{C}\right)$. X-ray diffractograms of the microcrystals contained three peaks, which were assigned to the 001,002 , and 003 reflections by comparing with CIF data and pulverized crystals recrystallized from a hexane solution. The top surface of the microcrystals was determined to be (001) face with its longitudinal direction along the $b$-axis, by comparison with plate-like bulk crystals obtained by recrystallization from a hexane solution. 


\section{a}

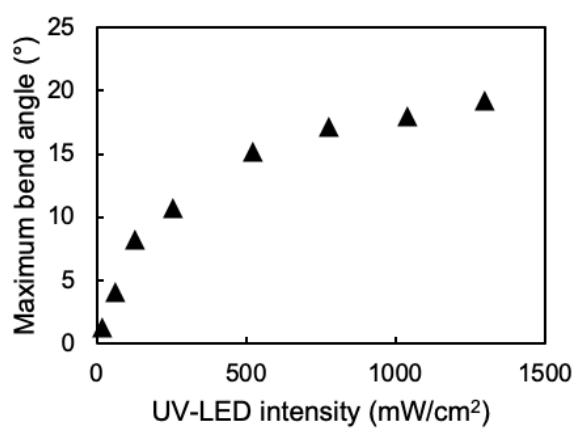

C

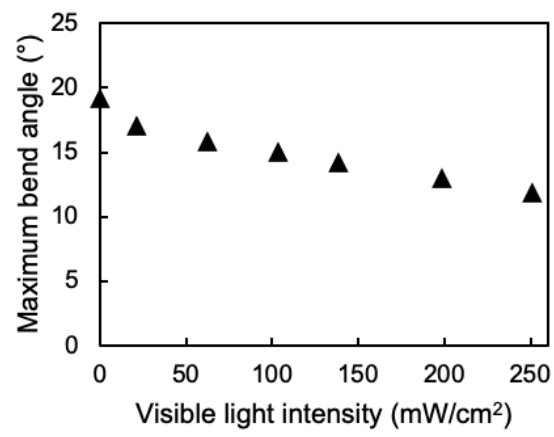

b

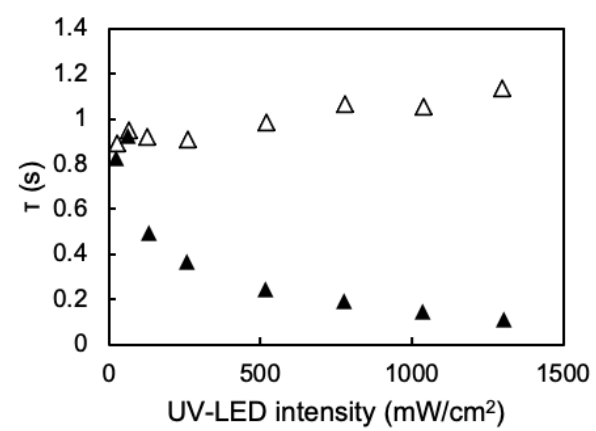

d

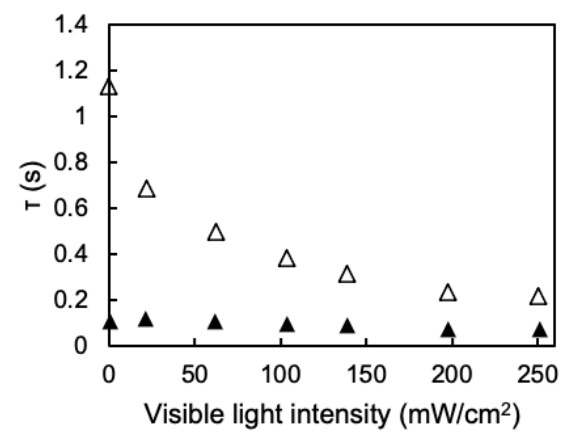

Figure S9. (a, b) UV-LED intensity dependence of (a) maximum bend angle and (b) time constant of a thin enol-1 crystal $\left(1170 \times 14.5 \times 10.2 \mu \mathrm{m}^{3}\right)$. (c, d) Visible light intensity dependence of (c) maximum bend angle and (d) time constant under continuous UV-LED $\left(365 \mathrm{~nm}, 1300 \mathrm{~mW} \mathrm{~cm}^{-2}\right.$, spot diameter $3.0 \mathrm{~mm}$ ) irradiation. (b, d) Black solid triangles and black open triangles represent time constants for bending and straightening, respectively. 
Table S4. Crystallographic constants of the enol-1 crystal before and under continuous UV light irradiation at $20^{\circ} \mathrm{C}$.

\begin{tabular}{llll}
\hline & Before UV irradiation & Under UV irradiation & Relative change [\%] \\
\hline Formula & $\mathrm{C}_{21} \mathrm{H}_{28} \mathrm{~N}_{2} \mathrm{O}$ & $\mathrm{C}_{21} \mathrm{H}_{28} \mathrm{~N}_{2} \mathrm{O}$ & - \\
Molecular weight & 324.46 & 324.46 & - \\
Crystal size $\left(\mu \mathrm{m}^{3}\right)$ & $1191 \times 153 \times 7$ & $1191 \times 153 \times 7$ & - \\
Temperature $\left({ }^{\circ} \mathrm{C}\right)$ & 20 & 20 & - \\
Crystal System & monoclinic & monoclinic & - \\
Space group & $P 21$ & $P 21$ & - \\
$a(\AA)$ & $10.9014(5)$ & $10.9003(5)$ & -0.010 \\
$b(\AA)$ & $6.2376(3)$ & $6.2379(2)$ & +0.005 \\
$c(\AA)$ & $15.0904(8)$ & $15.1009(8)$ & +0.070 \\
$\beta\left({ }^{\circ}\right)$ & $108.967(5)$ & $108.982(5)$ & +0.014 \\
$V\left(\AA^{3}\right)$ & $970.41(9)$ & $970.95(8)$ & +0.056 \\
$Z$ & 2 & 2 & - \\
$\rho_{\text {calc }}\left(\mathrm{g} \cdot \mathrm{cm}^{-3}\right)$ & 1.110 & 1.110 & - \\
$R_{I}[I>2 \sigma(I)]$ & 0.0644 & 0.0688 & - \\
$w R[I>2 \sigma(I)]$ & 0.1978 & 0.2093 & - \\
$G O F$ & 1.086 & 1.040 & - \\
\hline
\end{tabular}

(UV light condition: $365 \mathrm{~nm}, 50 \mathrm{~mW} \mathrm{~cm}^{-2}$ )
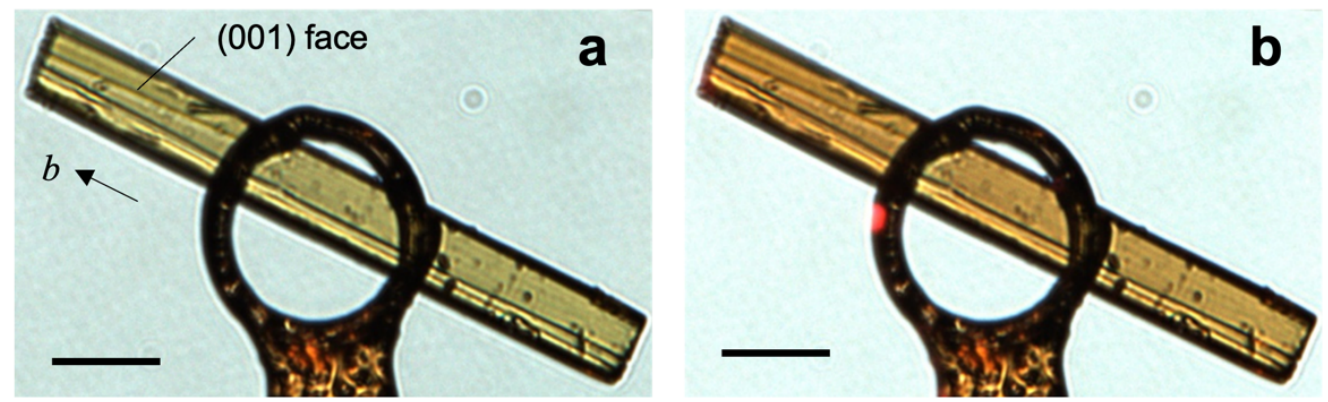

A thin plate-like enol-1 crystal (a) before and (b) under UV light (365 nm, $\left.50 \mathrm{~mW} \mathrm{~cm}{ }^{-2}\right)$ irradiation. Scale bars are $200 \mu \mathrm{m}$. 
Table S5. Distances, angles, and occupancies before and under continuous UV light irradiation at $20^{\circ} \mathrm{C}$.

\begin{tabular}{llll}
\hline Temperature $\left({ }^{\circ} \mathrm{C}\right)$ & Before UV irradiation & Under UV irradiation & Relative change [\%] \\
\hline $\mathrm{N}=\mathrm{C}$ bond length $(\AA)$ & 1.276 & 1.286 & +0.78 \\
$\mathrm{C}-\mathrm{O}$ bond length $(\AA)$ & 1.353 & 1.351 & -0.15 \\
$\begin{array}{l}\text { Intramolecular hydrogen bond } \\
\text { distance }(\mathrm{N}---\mathrm{O})(\AA)\end{array}$ & 2.603 & 2.610 & +0.27 \\
$\begin{array}{l}\text { Intramolecular hydrogen bond } \\
\text { distance }(\mathrm{N}---\mathrm{H}-\mathrm{O})(\AA)\end{array}$ & 1.874 & 1.877 & +0.16 \\
$\begin{array}{l}\text { Intramolecular molecular } \\
\text { hydrogen bond angle } \mathrm{N}---\mathrm{H}-\mathrm{O}\left({ }^{\circ}\right)\end{array}$ & 147.44 & 148.30 & +0.58 \\
$\begin{array}{l}\text { Intermolecular hydrogen bond } \\
\text { distance }(\mathrm{N}---\mathrm{O})(\AA)\end{array}$ & 3.341 & 3.334 & -0.21 \\
$\begin{array}{l}\text { Intermolecular hydrogen bond } \\
\text { distance }(\mathrm{N}-\mathrm{H}---\mathrm{O}) / \AA\end{array}$ & 2.605 & 2.628 & +0.21 \\
$\begin{array}{l}\text { Intermolecular hydrogen bond } \\
\text { angle } \mathrm{N}-\mathrm{H}---\mathrm{O}\left({ }^{\circ}\right)\end{array}$ & 143.51 & 137.57 & -4.14 \\
$\begin{array}{l}\text { Dihedral angle between phenyl } \\
\text { and salicyl planes }\left({ }^{\circ}\right)\end{array}$ & 35.12 & 35.04 & -0.23 \\
$\begin{array}{l}\text { Occupancy of disordered tert- } \\
\text { butyl group }(\%)\end{array}$ & $87.3: 12.7$ & $58.4: 41.6$ & - \\
\hline
\end{tabular}


a

\begin{tabular}{llll}
\hline & $\begin{array}{l}\text { Before UV irradiation } \\
(\mathrm{n}=9)(\sigma)\end{array}$ & $\begin{array}{l}\text { Upon UV irradiation } \\
(\mathrm{n}=13)(\sigma)\end{array}$ & $\begin{array}{l}\text { Relative } \\
\text { change [\%] }\end{array}$ \\
\hline Formula & $\mathrm{C}_{21} \mathrm{H}_{28} \mathrm{~N}_{2} \mathrm{O}$ & $\mathrm{C}_{21} \mathrm{H}_{28} \mathrm{~N}_{2} \mathrm{O}$ & - \\
Molecular weight & 324.46 & 324.46 & - \\
Crystal size $\left[\mu \mathrm{m}^{3}\right]$ & $1191 \times 153 \times 7$ & $1191 \times 153 \times 7$ & - \\
Temp $\left[{ }^{\circ} \mathrm{C}\right]$ & 20 & 20 & - \\
$\mathrm{a}[\AA]$ & $10.920(3)$ & $10.913(3)$ & -0.069 \\
$\mathrm{~b}[\AA]$ & $6.257(6)$ & $6.261(6)$ & +0.062 \\
$\mathrm{c}[\AA]$ & $15.104(6)$ & $15.099(7)$ & -0.034 \\
$\alpha\left[^{\circ}\right]$ & $89.988(68)$ & $90.025(54)$ & +0.059 \\
$\beta\left[{ }^{\circ}\right]$ & $108.943(40)$ & $108.965(67)$ & +0.021 \\
$\gamma\left[^{\circ}\right]$ & $90.006(64)$ & $90.022(60)$ & -0.009 \\
$\mathrm{~V}\left[\AA^{3}\right]$ & $975.7(7)$ & $975.1(12)$ & -0.079 \\
\hline $\mathrm{b}:$ Average $\pm \mathrm{SE}[\AA]$ & $6.257 \pm 0.002$ & $6.261 \pm 0.0017$ & - \\
\hline
\end{tabular}

$(\sigma)$ : Standard deviation

b

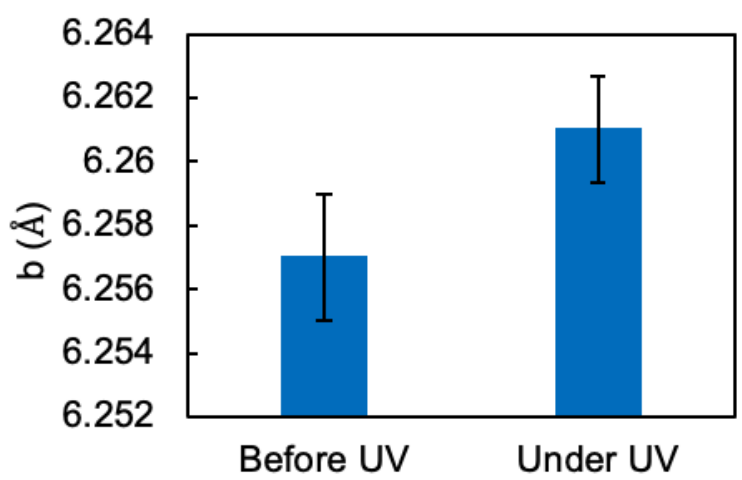

Figure S10. (a) Changes of unit cell parameters and (b) statistical evaluation of the change of $b$-axis length before $(\mathrm{n}=9)$ and under $(\mathrm{n}=13) \mathrm{UV}$ light $\left.(365 \mathrm{~nm}, 50 \mathrm{~mW} \mathrm{~cm})^{-2}\right)$ irradiation at $20{ }^{\circ} \mathrm{C}$. The increase of the $b$-axis length under UV light irradiation was significant as shown in (b). 

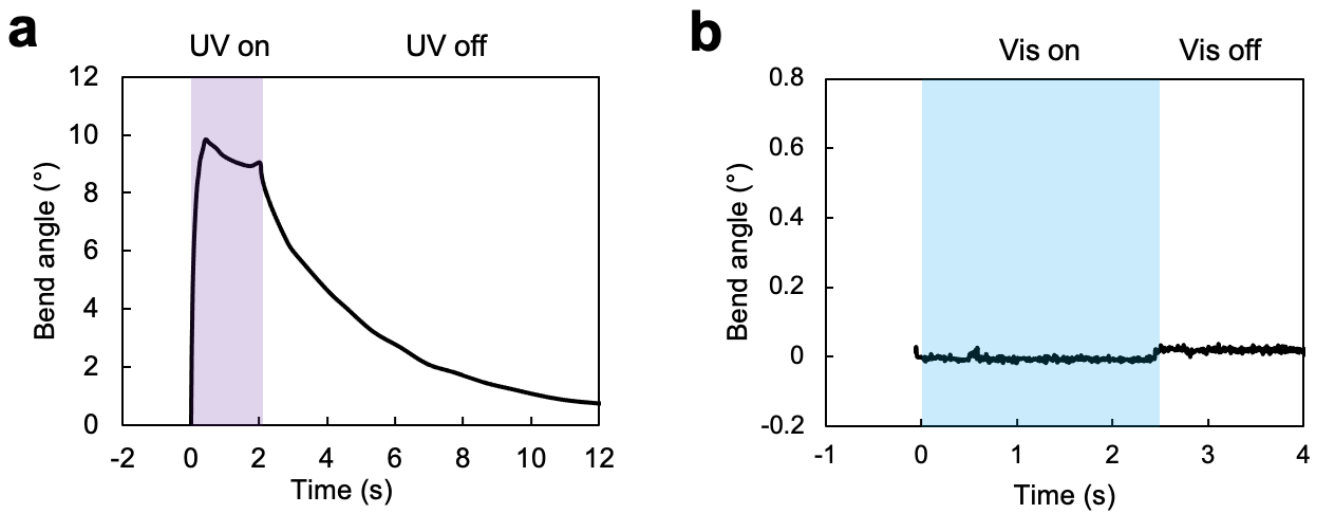

Figure S11. Comparison of bending of a thin enol-1 crystal $\left(470 \times 18.0 \times 7.2 \mu \mathrm{m}^{3}\right)$ upon irradiation with (a) UV (365 nm, $1300 \mathrm{~mW} \mathrm{~cm}^{-2}$ ) and (b) visible laser (488 nm, $280 \mathrm{~mW} \mathrm{~cm}^{-2}$ ) light. The crystal did not bend by visible light because of the lack of photoisomerization. 


\section{Estimation of photoreacted layer thickness by Timoshenko's bimetal model}

The bending mechanism induced by photoisomerization of molecules can be explained by the heterogeneous photo-reactivity between irradiated front surface and back surface (Figure S12). According to the literature ${ }^{8-10}$, the initial velocity of the curvature change ( $\left.V_{\text {init }}\right)$ and the thickness of photoreacted layer $\left(h_{2}\right)$ are related by the simplified Timoshenko's bimetal model.

$$
\begin{gathered}
V_{\text {init }}=\left.\frac{d(1 / R)}{d t}\right|_{t=0} \\
=\frac{\alpha_{2, \text { init }}}{h_{2}} \frac{6 m(1+m)}{1+4 m+6 m^{2}+4 m^{3}+m^{4}}
\end{gathered}
$$

in which

$$
m=\frac{h_{1}}{h_{2}}
$$

where $R$ is the curvature by photoisomerization alone, $t$ is irradiation time, $\alpha_{2}$, init is the initial velocity of the actuation strain change of the photoreacted layer, and $h_{1}$ and $h_{2}$ represent the thickness of the non photoreacted layer and the photoreacted layer, respectively. The values of $h_{2}$ and $\alpha_{2}$, init can be obtained by the best fitting curve (Eq. S1) to the experimental data.

Figure $\mathrm{S} 12 \mathrm{~b}$ shows the measured initial velocity of the curvature change $\left(V_{\text {init }}\right)$ of five crystals with different thickness. Here we discuss the bending behavior induced by photoisomerization alone and excluded the curvature change by the photothermal effect. The five dots were fitted by Eq. S1, giving the thickness of photoreacted layer $h_{2}: 2.64 \mu \mathrm{m}$ and the initial velocity of the actuation strain change of the photoreacted layer $\alpha_{2}$, init: $5.36 \% \mathrm{~s}^{-1}$.

a

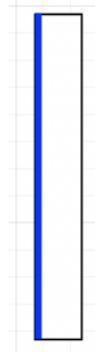

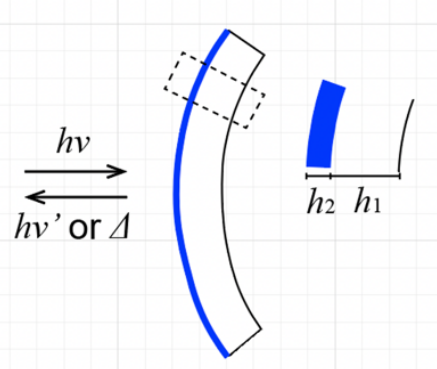

b

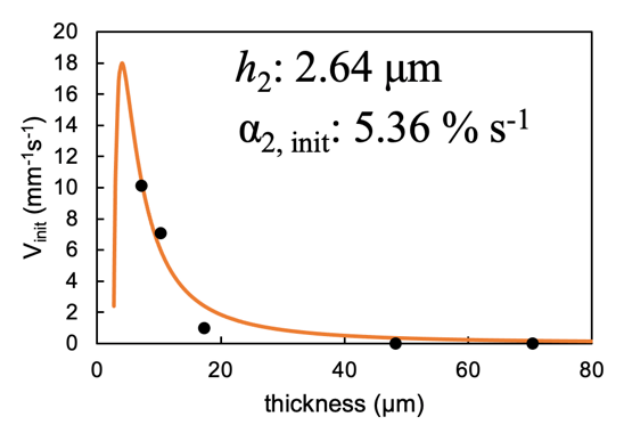

Figure S12. (a) Schematic illustration of Timoshenko's bimetal model. (b) Thickness dependence of the initial speed ( $\left.V_{\text {init }}\right)$ of the curvature change of the enol-1 crystal by photoisomerization alone (Figure S15 No. a, b, c, g, h). The solid orange line indicates fitting curve calculated by the bimetal model. 


\section{Crystal bending by the photothermal effect}

a

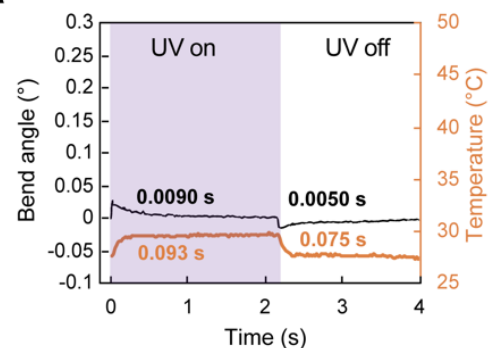

C

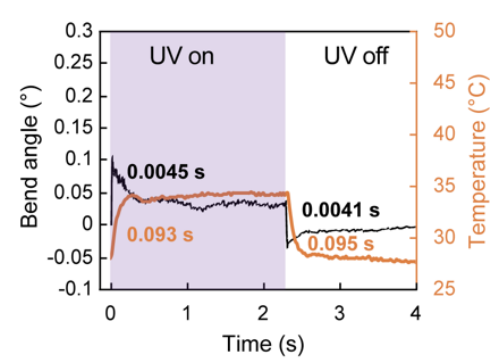

f

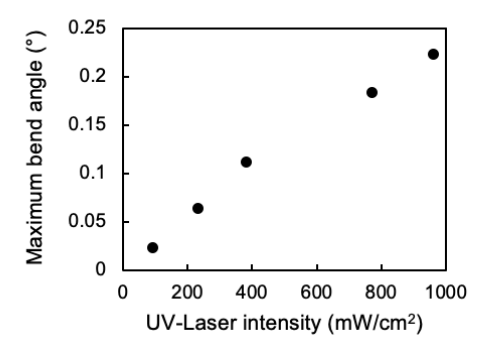

b

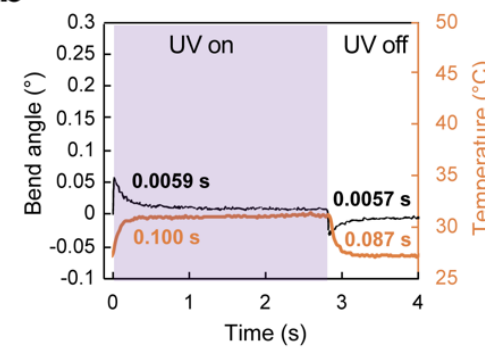

d
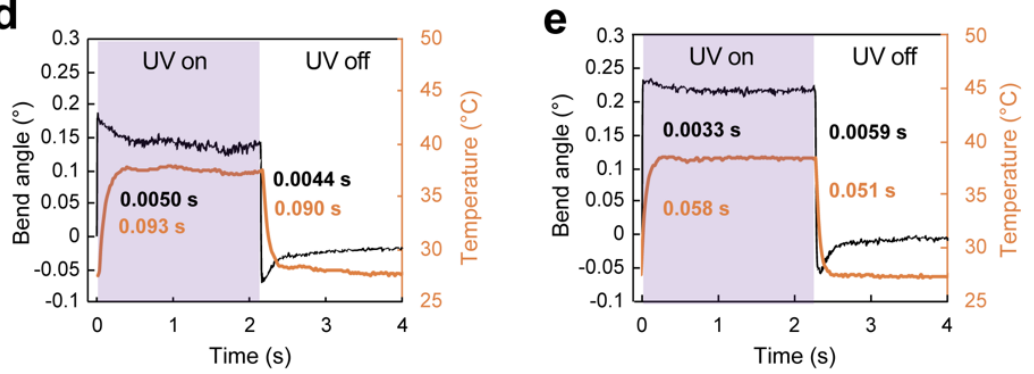

g

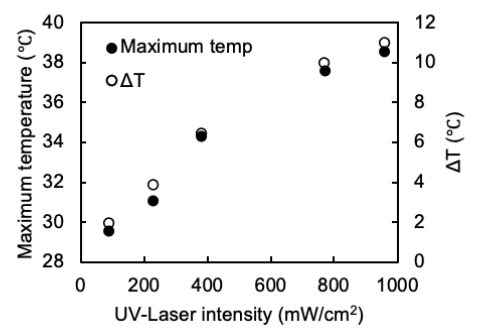

Figure S13. (a-e) Time dependence of bend angle (black line) and top surface temperature (orange line) of an enol-1 crystal $\left(1520 \times 68.0 \times 48.3 \mu^{3}\right)$ by UV laser $(375 \mathrm{~nm}$, spot diameter $2.6 \mathrm{~mm})$ with intensity of (a) $90 \mathrm{~mW} \mathrm{~cm}^{-2}$, (b) $230 \mathrm{~mW} \mathrm{~cm}^{-2}$, (c) $380 \mathrm{~mW} \mathrm{~cm}^{-2}$, (d) $770 \mathrm{~mW} \mathrm{~cm} \mathrm{~m}^{-2}$, (e) 960 $\mathrm{mW} \mathrm{cm}{ }^{-2}$. The numbers in the graphs indicate time constants. (f, g) UV laser intensity dependence of (f) maximum bend angle at steady state and ( $\mathrm{g}$ ) maximum temperature (black solid circle) and temperature increase (black open circle) on the irradiated top surface. 

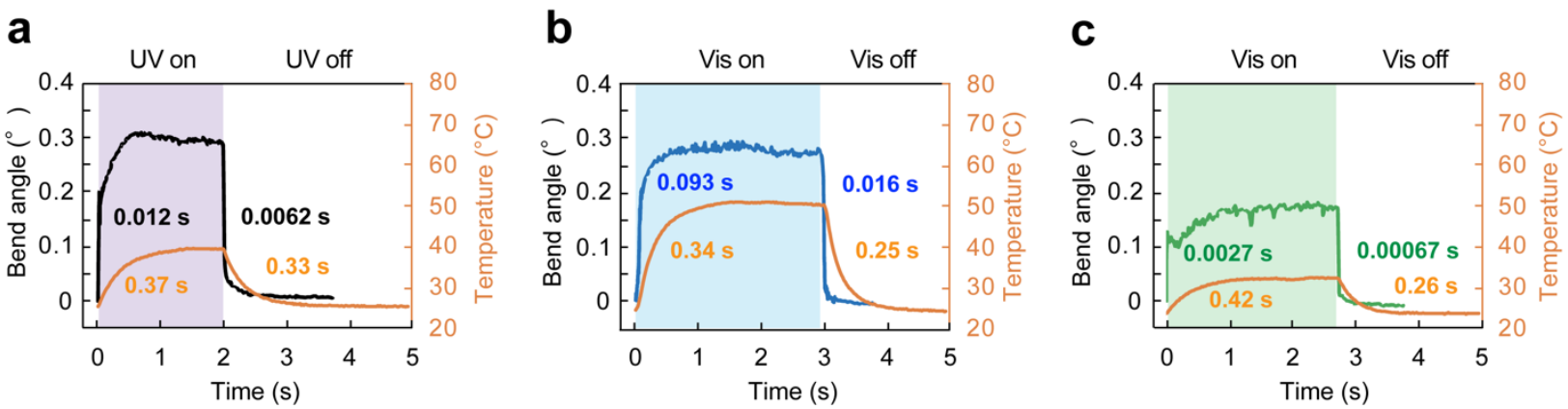

Figure S14. Time dependence of bend angle and the top surface temperature (orange) of an enol-1 crystal $\left(1700 \times 248 \times 70.4 \mu^{3}\right)$ upon (a) UV-LED $\left(365 \mathrm{~nm}, 520 \mathrm{~mW} \mathrm{~cm}^{-2}\right)$, (b) visible laser (488 $\mathrm{nm} 280 \mathrm{~mW} \mathrm{~cm}^{-2}$ ) (Movie S3), and (c) visible laser (520 nm, $1750 \mathrm{~mW} \mathrm{~cm}^{-2}$ ) irradiation. The numbers in the figures indicate time constants. 


\section{A: Bending by photoisomerization}
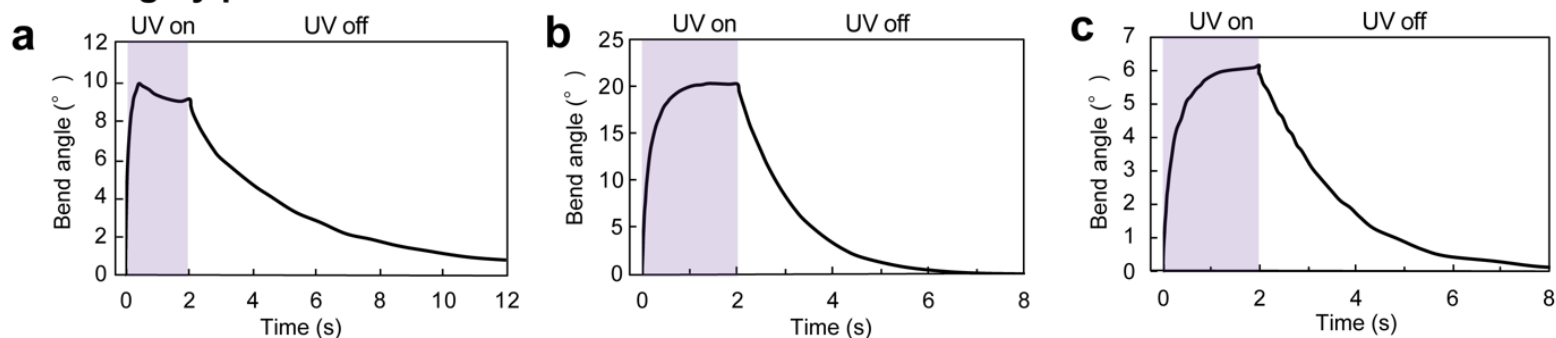

B: Two-step bending by photoisomerization and the photothermal effect
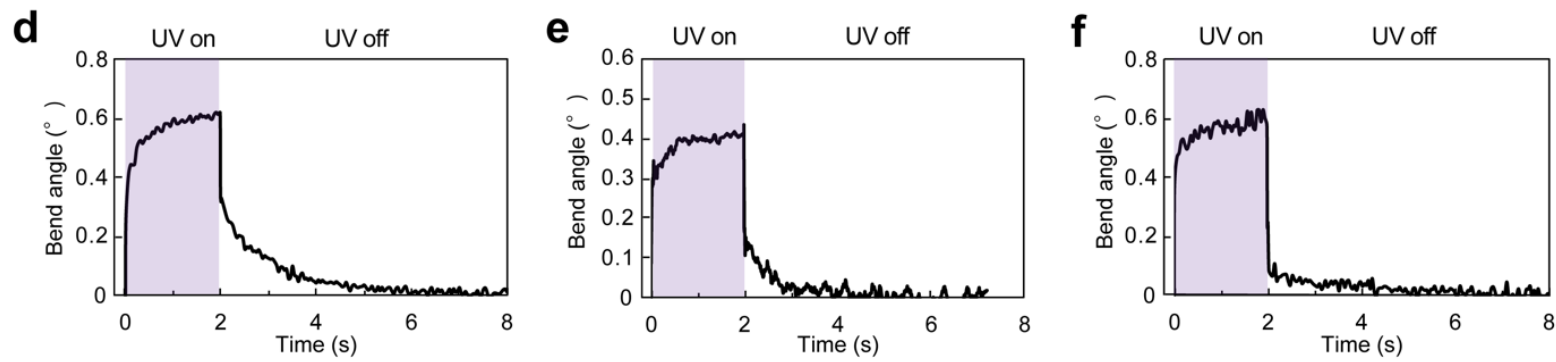

\section{C: Fast bending by the photothermal effect}
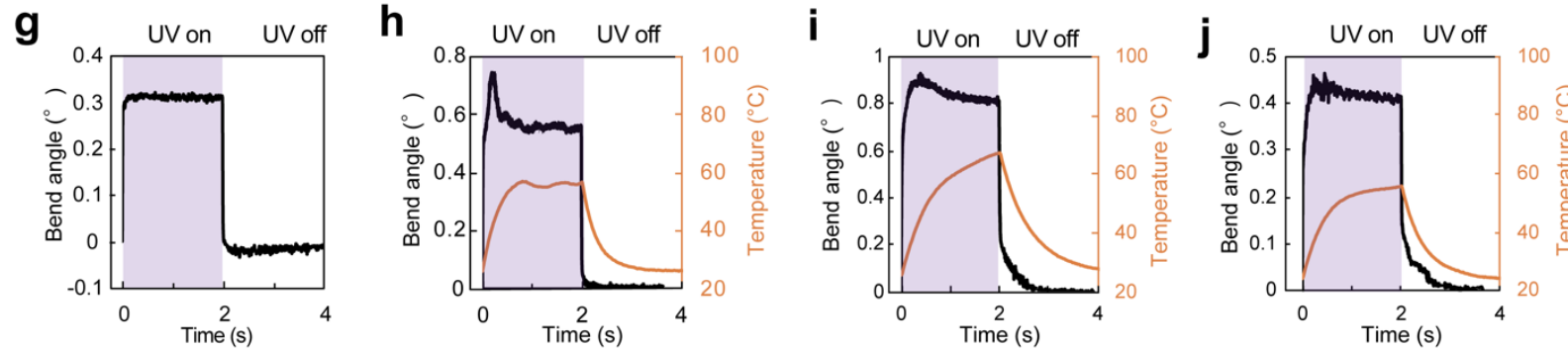

\begin{tabular}{|c|c|c|c|c|c|c|c|c|c|c|c|}
\hline \multirow{3}{*}{ No. } & \multirow{3}{*}{ Length } & \multicolumn{2}{|c|}{ Size $\left(\mu \mathrm{m}^{3}\right)$} & \multirow{3}{*}{$\begin{array}{l}\text { Aspect ratio } \\
\text { (Length/ } \\
\text { Thickness) }\end{array}$} & \multirow{3}{*}{ Weight $(\mu \mathrm{g})$} & \multicolumn{2}{|c|}{ Maximum bend angle $\left({ }^{\circ}\right)$} & \multirow{2}{*}{\multicolumn{2}{|c|}{$\begin{array}{c}\text { Time constant (s) } \\
\text { Photoisomerization }\end{array}$}} & \multirow{2}{*}{\multicolumn{2}{|c|}{$\begin{array}{c}\text { Time constant (ms) } \\
\text { Photothermal effect }\end{array}$}} \\
\hline & & & & & & Photoiso- & Photother- & & & & \\
\hline & & Width & Thickness & & & merization & mal effect & Bending & Straightening & Bending & Straightening \\
\hline $\mathrm{a}$ & 470 & 18.0 & 7.2 & 65.28 & 0.0676 & 9.34 & 0 & 0.072 & 3.51 & & \\
\hline $\mathrm{b}$ & 1169 & 14.5 & 10.2 & 114.6 & 0.1919 & 19.6 & 0 & 0.15 & 1.11 & & \\
\hline $\mathrm{c}$ & 1662 & 42.6 & 17.8 & 93.37 & 1.3989 & 5.75 & 0 & 0.19 & 1.66 & & \\
\hline d & 1270 & 35.1 & 22.3 & 56.95 & 1.1034 & 0.25 & 0.36 & 0.33 & 1.12 & 3.8 & 1.0 \\
\hline e & 1193 & 37.8 & 25.4 & 46.97 & 1.2714 & 0.15 & 0.26 & 0.23 & 0.52 & 1.2 & 1.9 \\
\hline $\mathrm{f}$ & 1912 & 48.2 & 35.4 & 54.01 & 3.6213 & 0.17 & 0.42 & 0.27 & 2.66 & 3.1 & 7.1 \\
\hline $\mathrm{g}$ & 1524 & 68.0 & 48.3 & 31.55 & 5.5560 & 0 & 0.31 & & & 4.1 & 2.6 \\
\hline $\mathrm{h}$ & 1770 & 248 & 70.4 & 25.14 & 34.302 & 0 & 0.56 & & & 8.7 & 8.9 \\
\hline $\mathrm{i}$ & 4835 & 280 & 82.4 & 58.68 & 123.82 & 0 & 0.90 & & & 8.0 & 11.0 \\
\hline $\mathrm{j}$ & 2490 & 355 & 105 & 23.71 & 103.02 & 0 & 0.43 & & & 4.4 & 6.9 \\
\hline
\end{tabular}

Figure S15. Relationship between crystal thickness and bending upon UV-LED (365 nm, $1300 \mathrm{~mW}$ $\mathrm{cm}^{-2}$, spot diameter $\left.3.0 \mathrm{~mm}\right)$ irradiation for $2 \mathrm{~s} . \mathrm{A}$ : $(\mathrm{a}-\mathrm{c})$ Bending by photoisomerization. B: $(\mathrm{d}-\mathrm{f})$ Two-step bending by photoisomerization and the photothermal effect. C: $(\mathrm{g}-\mathrm{j})$ Fast bending by the photothermal effect. 
Continued explanation of Figure S15:

For crystals showing two-step bending (Figure S15B), the contributions of photoisomerization and the photothermal effect were separated as follows; time dependence of bend angle was fitted by a biexponential equation and the fast component was regarded as the contribution of the photothermal effect and the slow component as that of photoisomerization.

\section{a}

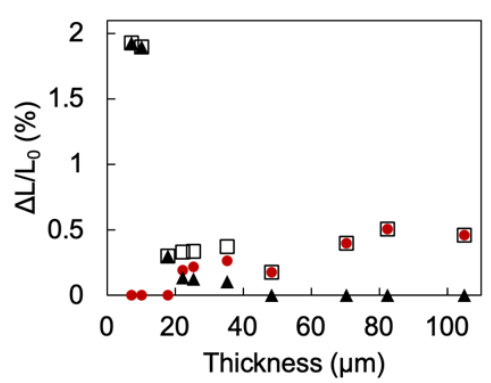

b

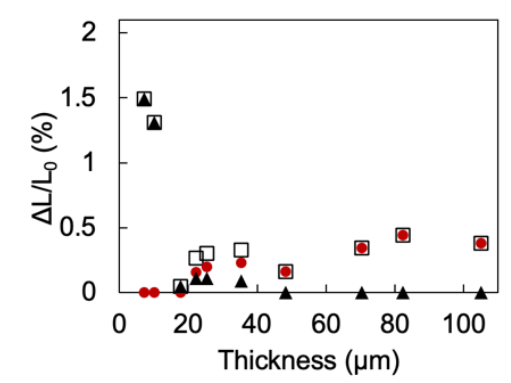

C

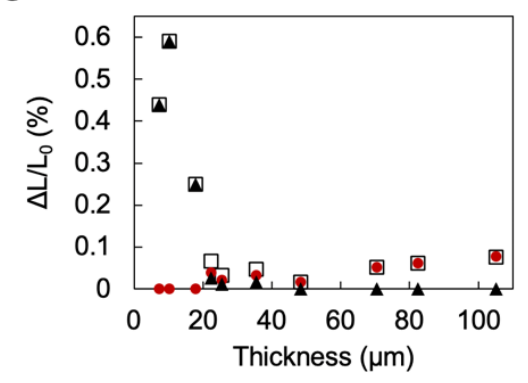

Figure S16. Thickness dependence of the change in the crystal length relative to the initial length for (a) top surface, (b) back surface, and (c) difference between top and back surface upon UV-LED (365 $\mathrm{nm}, 1300 \mathrm{~mW} \mathrm{~cm}{ }^{-2}$, spot diameter $3.0 \mathrm{~mm}$ ) irradiation for $2 \mathrm{~s}$. Black solid triangles, red solid circles, and black open squares indicate the contribution of photoisomerization, the photothermal effect, and sum of photoisomerization and the photothermal effect, respectively. 
a

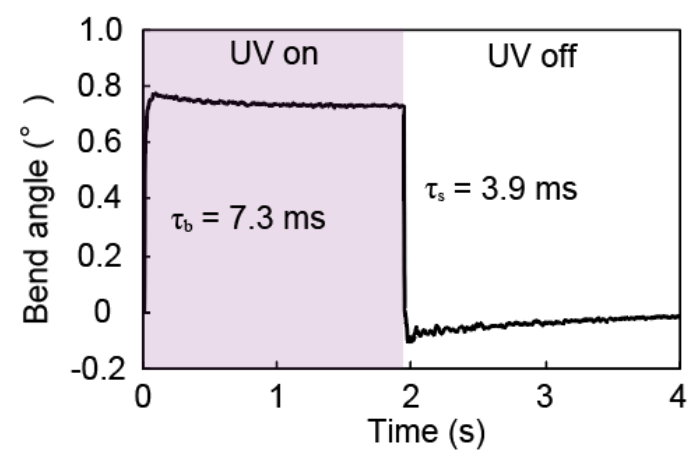

b

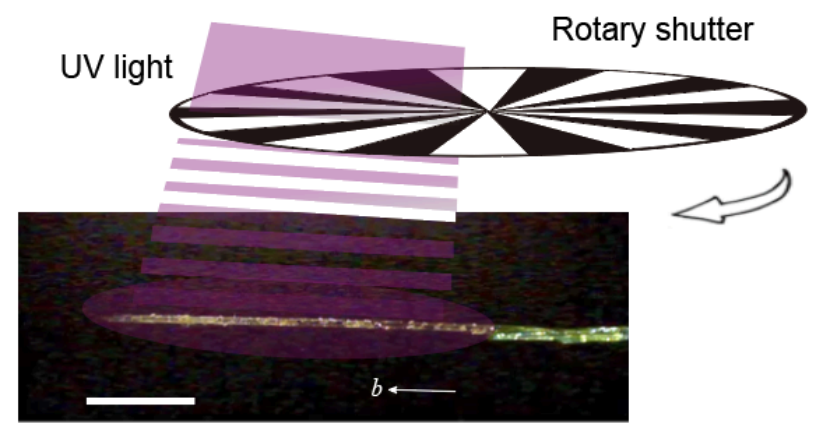

Figure S17. High-frequency bending of a thick enol-1 crystal $\left(1912 \times 48.2 \times 35.4 \mu \mathrm{m}^{3}\right)$ by the photothermal effect. (a) Time dependence of bend angle upon UV laser $\left(375 \mathrm{~nm}, 960 \mathrm{~mW} \mathrm{~cm}{ }^{-2}\right.$, spot diameter: $2.6 \mathrm{~mm}$ ) for $2 \mathrm{~s}$. (b) Experimental setup. The scale bar is $500 \mu \mathrm{m}$. 


\section{Estimation of photothermal energy generated inside crystal}

Here we estimate photothermal energy $Q_{\text {total }}$ generated inside a crystal upon light irradiation via the nonradiative deactivation process of $c i s-k e t o-1 *$ to cis-keto-1. First, we partition the domain in space (i.e. thickness) into meshes $\left(x_{\mathrm{i}}, i=0,1,2 \ldots, N\right)$ and calculate thermal energy generated from a single mesh (Figure S18):

$$
Q_{g e n}(i)=C N_{P}(i)=C N_{i r r} \exp (-\mu i \Delta x)
$$

in which

$$
C=\left(1-\emptyset_{F}\right) E_{561} \mu A \Delta t \Delta x
$$

where $Q_{\text {gen }}(i)$ represents photothermal energy generated from a mesh $x_{\mathrm{i}}, N_{P}(i)$ is the number of photons per unit time and unit area at the front surface of a mesh, $N_{\text {irr }}$ is the number of photons per unit time and unit area at the irradiated front surface $\left(365 \mathrm{~nm}, 1300 \mathrm{~mW} \mathrm{~cm}{ }^{-2}: 2.389 \times 10^{22} \mathrm{~m}^{-2} \mathrm{~s}^{-1}\right)$, $i \Delta x$ is the depth of a mech from the front surface, and $\mu$ is the absorption coefficient of the single crystal $\left(3.79 \times 10^{5} \mathrm{~m}^{-1}\right)$, determined by inverting the thickness of photoreacted layer $\left(h_{2}: 2.64 \mu \mathrm{m}\right)$ (see Figure S12).

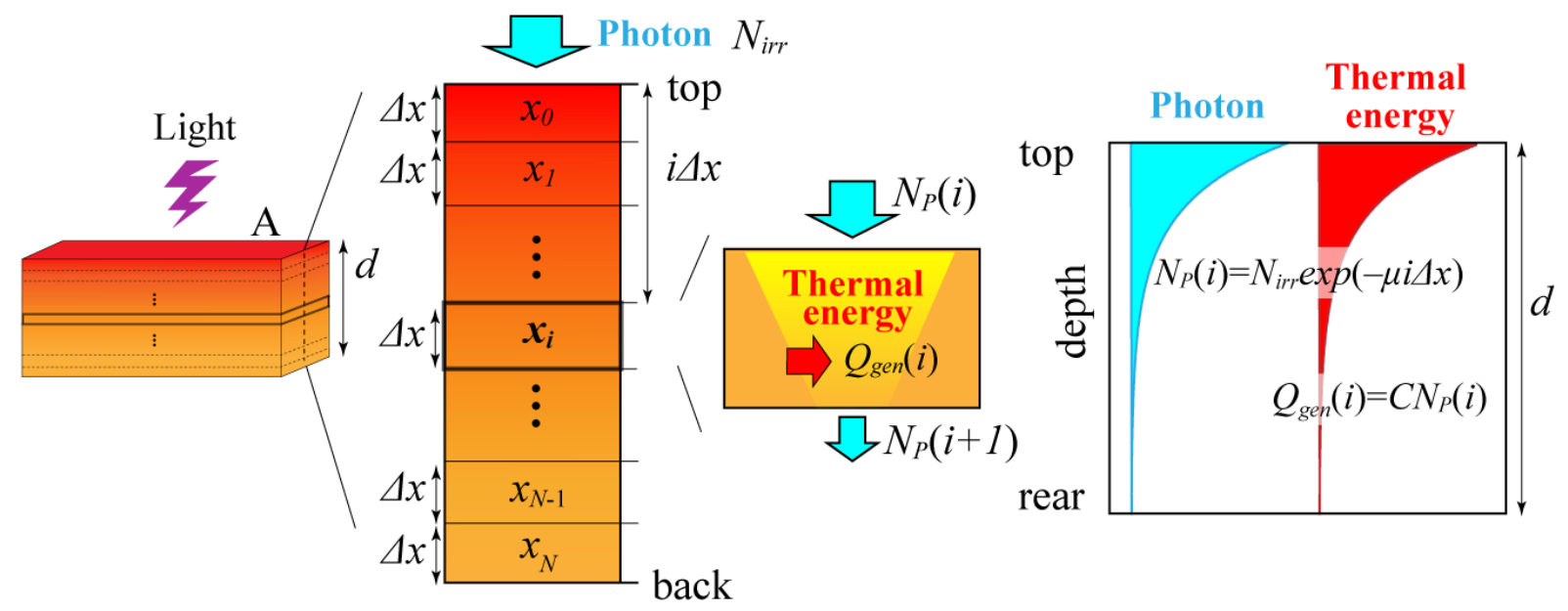

Figure S18. Schematic illustration for heat generation from a single mesh upon light irradiation. The number of photons per unit area, $N_{P}(i)$ and thermal energy generated from a single mesh, $Q_{g e n}(i)$ decrease exponentially with depth.

$\Phi_{F}$ is the fluorescence quantum yield (0.006) of cis-keto-1* to cis-keto-1, which was determined with absolute photoluminescence quantum yield spectrometer. $E_{561}$ is photon energy at $561 \mathrm{~nm}$ $\left(3.541 \times 10^{-19} \mathrm{~J}\right)$ (see Figure $\left.\mathrm{S} 19\right) . A$ is the surface area, $\Delta t$ is the light irradiation time, and $\Delta x$ is the thickness of a mesh. 


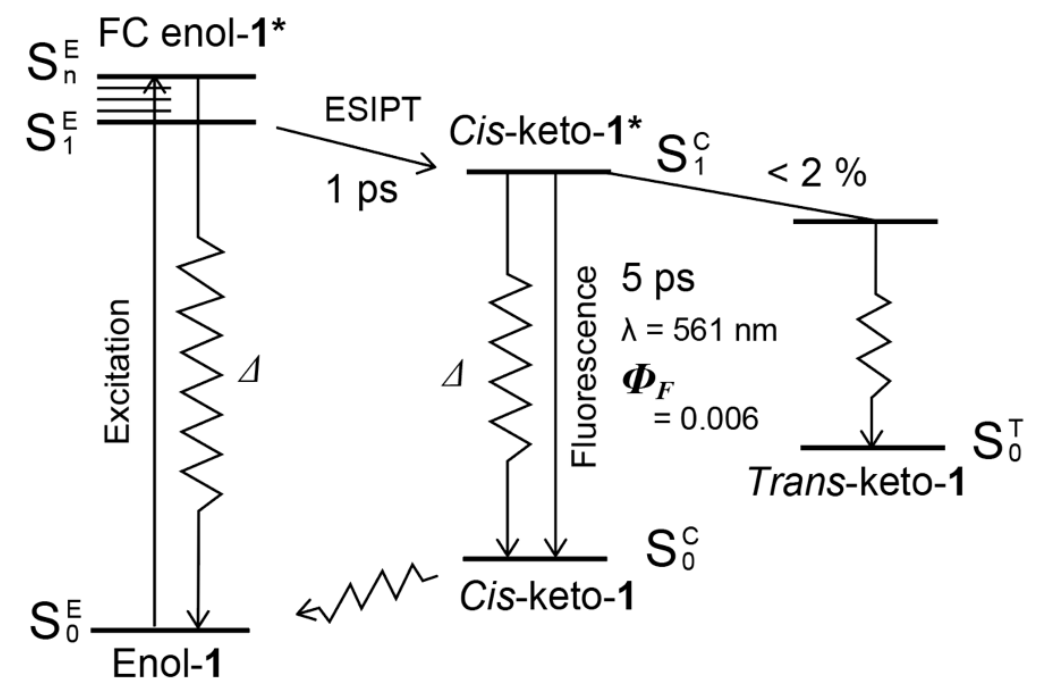

Figure S19. Photodynamics of enol-1 crystal following photoexcitation. Photothermal energy generated via nonradiative deactivation of cis-keto-1* was calculated based on the fluorescence quantum yield of cis-keto-1* to cis-keto-1 ( $\left.\Phi_{F}\right)$ and wavelength of the fluorescence $(561 \mathrm{~nm})$.

Using Eq. S3 and S4, the total energy generated inside the crystal is represented as

$$
Q_{\text {total }}=\sum_{i=0}^{N} Q_{\text {gen }}(i)=\sum_{i=0}^{N} C^{\prime} \exp \left(-\mu \frac{i d}{N+1}\right) \frac{d}{N+1}
$$

where

$$
C^{\prime}=C \frac{N_{i r r}}{\Delta x}=\left(1-\emptyset_{F}\right) E_{561} \mu A \Delta t N_{i r r}
$$

According to Gaussian Quadrature method, Eq. S5 gives

$$
\begin{gathered}
Q_{\text {total }}=\lim _{N \rightarrow \infty} \sum_{i=0}^{N} C^{\prime} \exp \left(-\mu \frac{i d}{N+1}\right) \frac{d}{N+1} \\
=\int_{0}^{d} C^{\prime} \exp (-\mu x) d x=C^{\prime} \frac{1}{\mu}\{1-\exp (-\mu d)\}
\end{gathered}
$$

Hence, the temperature increase of the crystal $\Delta T_{\text {total }}$ is calculated as

$$
\begin{gathered}
\Delta T_{\text {total }}=\frac{Q_{\text {total }}}{C_{p} \rho A d}=\frac{C^{\prime} \frac{1}{\mu}\{1-\exp (-\mu d)\}}{C_{p} \rho A d} \\
=\frac{\left(1-\emptyset_{F}\right) E_{561} \Delta t N_{i r r}\{1-\exp (-\mu d)\}}{C_{p} \rho d}
\end{gathered}
$$


where $C_{p}$ is the heat capacity at constant pressure $\left(1.65 \mathrm{~J} \mathrm{~K}^{-1} \mathrm{~g}^{-1}\right), \rho$ is the density of the crystal $(1.11$ $\left.\mathrm{g} \mathrm{cm}^{-3}\right)$.

Eq. S8 gives temperature velocity of temperature increase as

$$
V=\frac{\Delta T_{\text {total }}}{\Delta t}=\frac{\left(1-\emptyset_{F}\right) E_{561} N_{\text {irr }}\{1-\exp (-\mu d)\}}{C_{p} \rho d}
$$

indicating that the crystal thickness $d$ and the velocity of temperature increase $V$ can be related with Eq. S9.

Figure S20 shows thickness dependence of the initial velocity of temperature increase $V_{\text {init }}$ of measured (Crystal size: $1770 \times 248 \times 70.4 \mu^{3}, 4835 \times 280 \times 82.4 \mu \mathrm{m}^{3}, 2490 \times 355 \times 105 \mu^{3}$, see Figure S15, h, i, j crystals) values and calculated values upon UV-LED $\left(365 \mathrm{~nm}, 1300 \mathrm{~mW} \mathrm{~cm}^{-2}\right)$ for $2 \mathrm{~s}$ based on Eq. S9. Because Eq. S9 does not take heat conduction or cooling from the outside air into consideration, we employed the initial velocity of temperature increase to compare the measured and calculated values quantitatively. The calculated $V_{\text {init }}$ were $61.6,52.7$, and $41.3 \mathrm{~K} \mathrm{~s}^{-1}$ for crystals with a thickness of 70.4, 82.4, and $105 \mu \mathrm{m}$, respectively (Figure S20, green line), which were smaller than the measured $V_{\text {init }}\left(121,68.4\right.$, and $74.8 \mathrm{~K} \mathrm{~s}^{-1}$, black circle). This result shows that more thermal energy is generated than the calculated value in the crystal, suggesting that thermal energy is generated not only from the nonradiative deactivation of excited cis-keto-1*, but also from the nonradiative deactivation of vertically excited FC enol-1* form.

Then, we estimated $Q_{\text {total }}$ under the consumption that all the absorbed light energy $(\lambda=365 \mathrm{~nm})$ was converted into thermal energy. In this case, Eq. S4 can be arranged as

$$
C=E_{365} \mu A \Delta t \Delta x
$$

where $E_{365}$ is photon energy at $365 \mathrm{~nm}\left(5.442 \times 10^{-19} \mathrm{~J}\right)$. The calculated $V_{\text {init }}$ were $95.3,81.0$, and 63.9 $\mathrm{K} \mathrm{s}^{-1}$ for crystals with a thickness of $70.4,82.4$, and $105 \mu \mathrm{m}$, respectively (Figure S20, purple line), which were comparable to the measured values (black circle), proving the validity of the hypothesis that most of the absorbed light energy was converted to the thermal energy in crystal. 


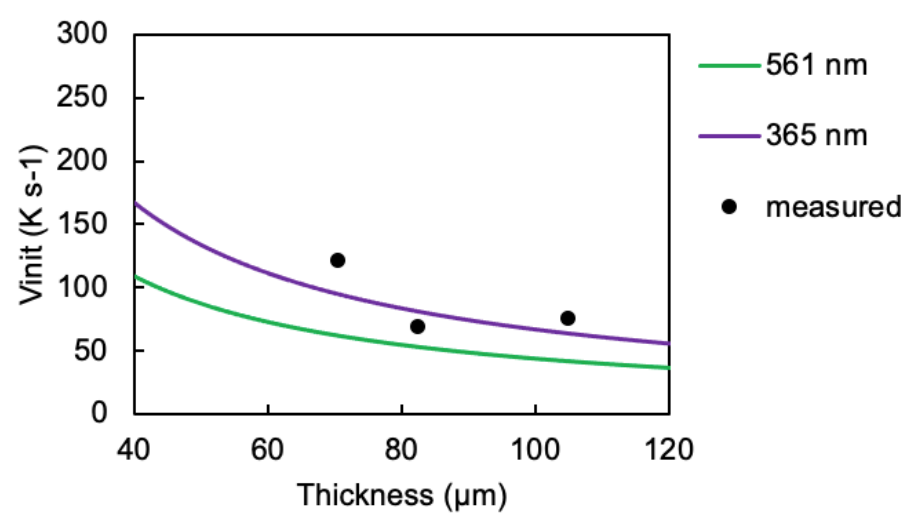

Figure S20. Thickness dependence of the initial velocity of temperature increase for enol-1 crystals upon UV-LED irradiation ( $365 \mathrm{~nm}, 1300 \mathrm{~mW} \mathrm{~cm}^{-2}$, spot diameter $3.0 \mathrm{~mm}$ ). Black circle indicates measured $V_{\text {init, }}$, green solid line represents $V_{\text {init }}$ calculated from the thermal energy generated via cisketo-1* to cis-keto-1 nonradiative deactivation process (fluorescence wavelength: $561 \mathrm{~nm}$ ), and purple solid line shows $V_{\text {init }}$ calculated from the thermal energy under the hypothesis that all absorbed light energy was converted to the thermal energy in crystal (irradiated light wavelength: $365 \mathrm{~nm})$. 


\section{Measurement of thermal diffusivity of the enol-1 crystal by TWA method}

Temperature wave analysis (TWA) method is one of the standard techniques for measuring thermal diffusivity, by employing the phase delay of temperature wave (Figure S21a). ${ }^{11-17}$ TWA method is advantageous for the measurement of micro-sized samples. Here, we determined the thermal diffusivity of an enol-1 crystal (thickness: $42.7 \mu \mathrm{m}$ ) in the thickness direction $c$-axis. The sample was set between a thin indium tin oxide (ITO) glass heater $\left(1000 \times 250 \mu^{2}\right)$ and a Ni-Au micro thermocouple sensor (Figure S21b). Sinusoidal waveform voltage was applied to ITO heater from a function synthesizer 1920A (NF Corporation) that generates a periodic heat flow; the thermoelectric sensor measured a periodical temperature change. The phase delay $(\Delta \theta)$ of the temperature waves between the heater and the sensor was measured with a lock-in amplifier SR830 (Stanford Research Systems) over several frequencies $(f)$. During the measurement the sample temperature was fixed by using a thermo-controller.

Thermal diffusivity was measured by frequency scan; temperature waves with different frequencies are applied to the sample at a constant temperature. The relationship among thermal diffusivity $\alpha$, phase delay $\Delta \theta$, and the frequency of the temperature wave $f$ can be described as in. Eq. S11 ${ }^{11,12}$ :

$$
\Delta \theta=-\sqrt{\frac{\pi f}{\alpha}} d+\beta
$$

where $d$ is the sample thickness and $\beta$ is the experimental constant value. At six temperatures (12.1, $\left.22.3,32.4,42.4,52.0,61.8^{\circ} \mathrm{C}\right)$, the phase delay and the square root of the frequencies of temperature wave were observed in the linear relationship in a frequency range from 55.9 to $223.5 \mathrm{~Hz}$ (Figure S22a). By using a linear slope $A$ in the plot of $\Delta \theta$ versus $f^{1 / 2}$, thermal diffusivity $\alpha$ can be determined on the basis of Eq. S12 11,12 :

$$
\alpha=\pi\left(\frac{d}{A}\right)^{2}
$$

The calculated thermal diffusivity values were $0.901( \pm 0.069), 0.874( \pm 0.074), 0.844( \pm 0.071), 0.806$ $( \pm 0.065), 0.774( \pm 0.058)$, and $0.735( \pm 0.062) \times 10^{-7} \mathrm{~m}^{2} \mathrm{~s}^{-1}$, respectively (Figure S22b), showing the linear temperature dependence change, $\alpha=\left(-0.0034 T\left[{ }^{\circ} \mathrm{C}\right]+0.9474\right) \times 10^{-7} \mathrm{~m}^{2} \mathrm{~s}^{-1}\left(\mathrm{R}^{2}=0.9956\right)$ (Figure S22c). 

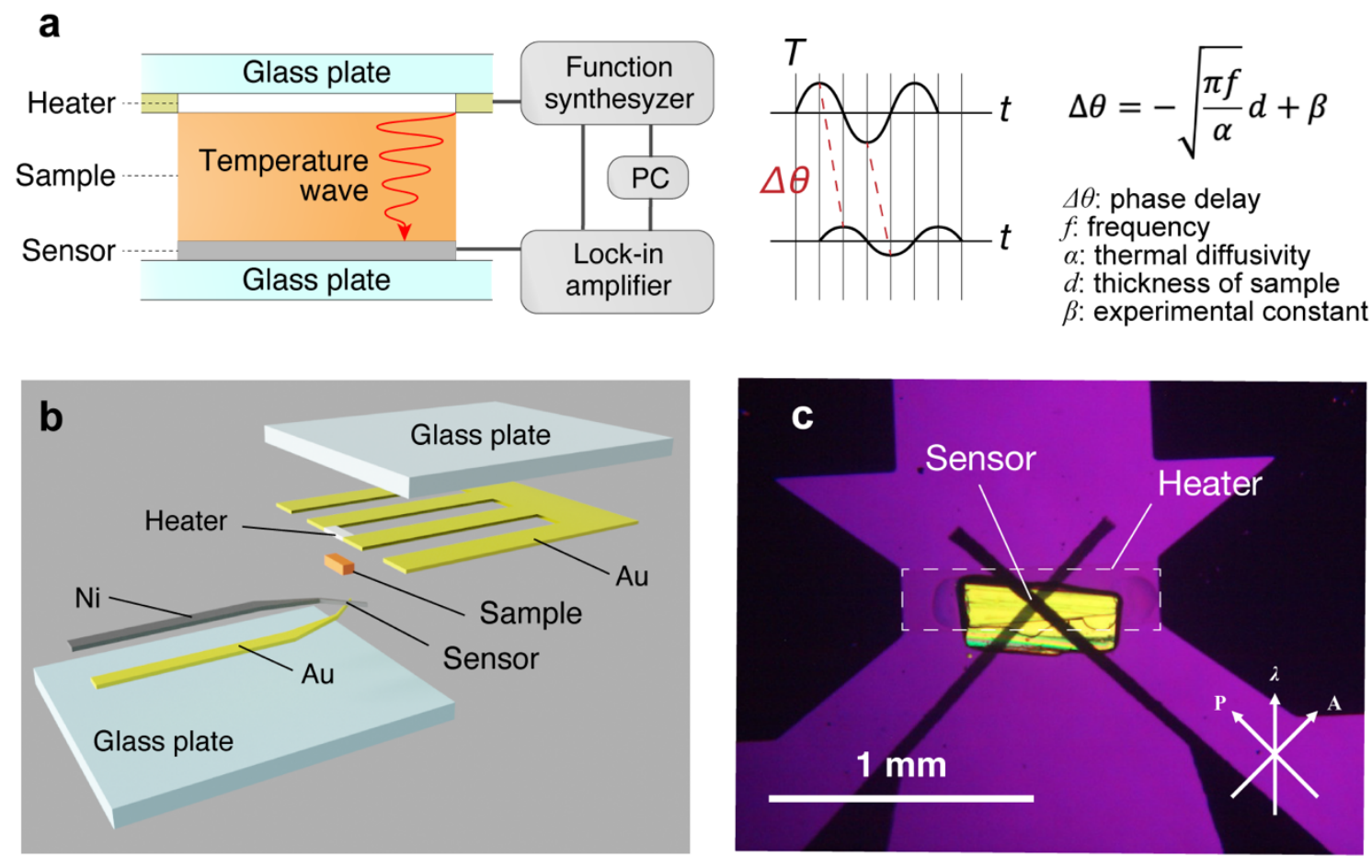

Figure S21. (a) Schematic diagram of the measurement principle of thermal diffusivity by temperature wave analysis (TWA) measurements. (b) Schematic assembly of samples for TWA measurements. A single crystal was set between indium tin oxide (ITO) glass heater and Ni-Au micro thermocouple sensor on glass plates. (c) Polarized photo of an enol-1 crystal (thickness $42.7 \mu \mathrm{m}$ ) between the heater and the sensor from the bottom (sensor) side. The crystal was placed at a $45^{\circ}$ angle from the direction of the polarizer $(\mathrm{P})$. 
a
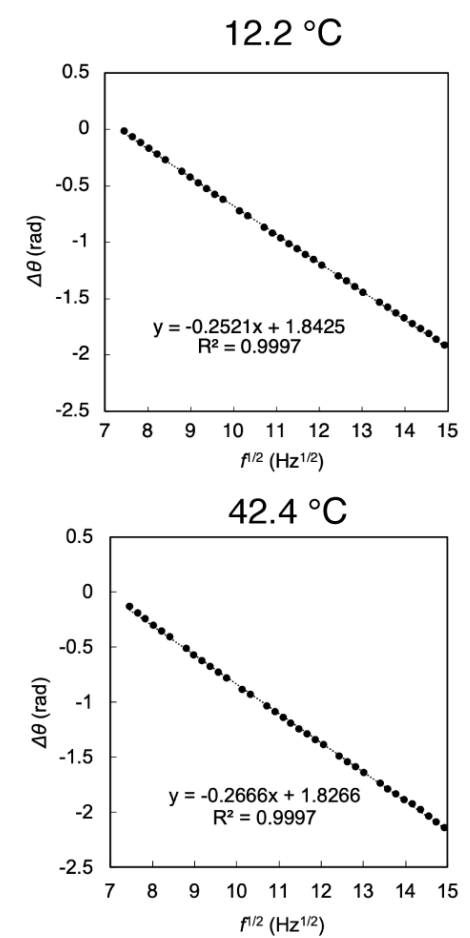

b

\begin{tabular}{ccc}
\hline Temperature $\left({ }^{\circ} \mathrm{C}\right)$ & $\begin{array}{c}\text { Thermal diffusivity } \\
\left(\times 10^{-7} \mathrm{~m}^{2} / \mathrm{s}\right)\end{array}$ & $\Delta a(\mathrm{SE})$ \\
\hline 12.1 & 0.901 & 0.069 \\
22.3 & 0.874 & 0.074 \\
32.4 & 0.844 & 0.071 \\
42.4 & 0.806 & 0.065 \\
52 & 0.774 & 0.058 \\
61.8 & 0.735 & 0.062 \\
\hline
\end{tabular}

${ }^{\star} \Delta a$ is calculated based on the propagation of error, $\Delta \mathrm{A}$ :

$$
\Delta \alpha=2 \alpha \sqrt{\left(\frac{\Delta A}{A}\right)^{2}} \quad \begin{gathered}
\text { A: slope of the } \Delta \theta-\sqrt{ } \text { plot } \\
\Delta \mathrm{A}: \text { propagation of error for A }
\end{gathered}
$$

$22.3^{\circ} \mathrm{C}$

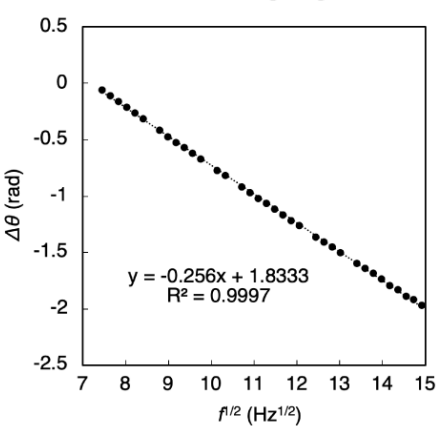

$52^{\circ} \mathrm{C}$

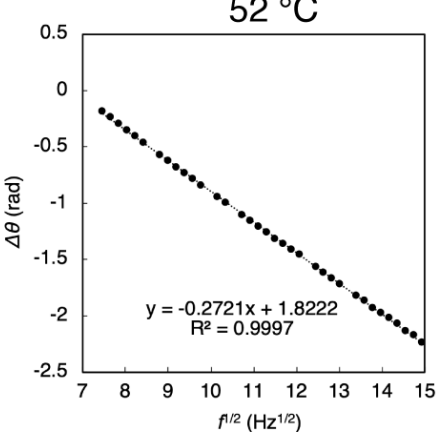

$32.4^{\circ} \mathrm{C}$
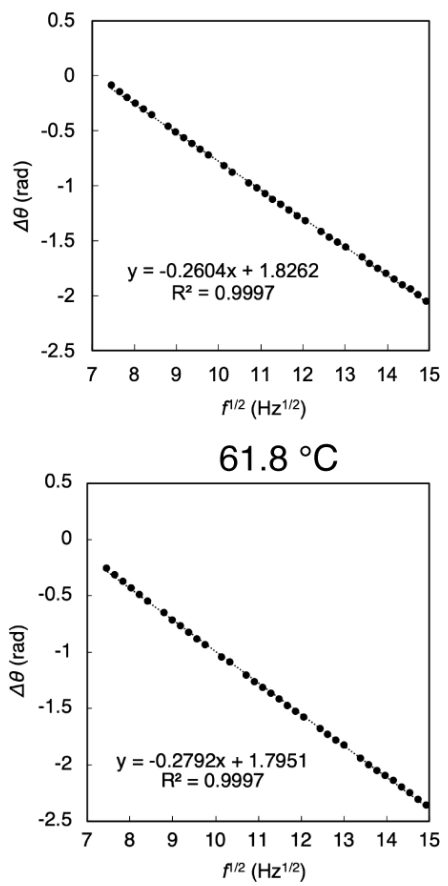

C

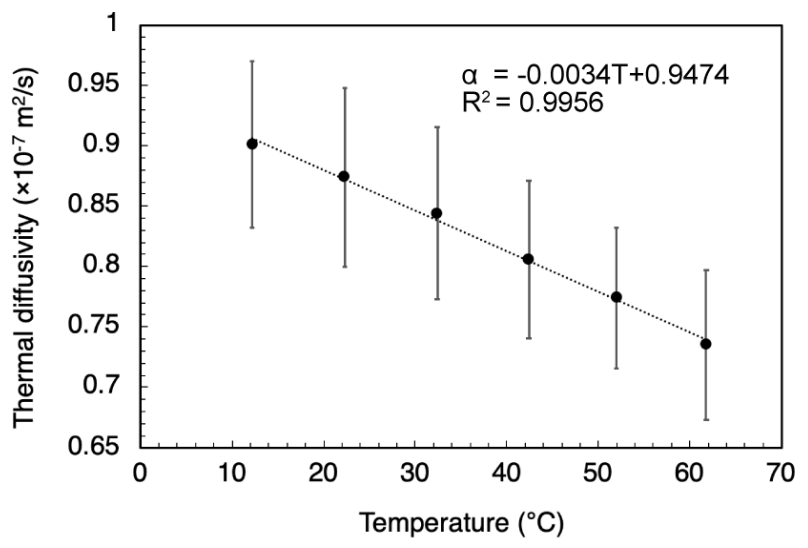

Figure S22. Thermal diffusivity of the enol-1 crystal along the thickness direction $c$-axis measured by TWA. (a) Relationship between the phase delay $\Delta \underline{\theta}$ and the square root of frequency of temperature wave $f^{1 / 2}$ and (b) measured thermal diffusivity $\alpha$ at various temperatures. $\Delta \alpha$ is the standard error of the thermal diffusivity calculated based on the propagation of error. (c) Temperature dependence of the thermal diffusivity. 
a

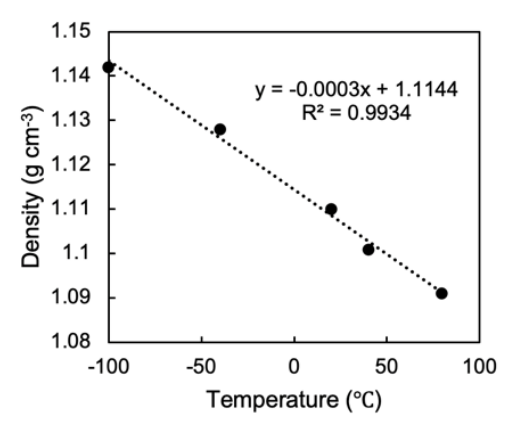

b

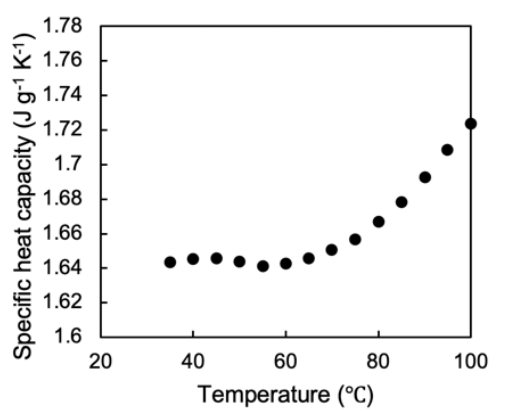

C

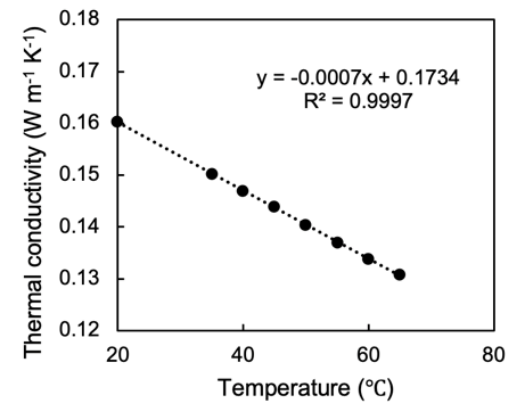

Figure S23. Temperature dependence of (a) density, (b) specific heat capacity, and (c) thermal conductivity of the enol-1 crystal along the thickness direction $c$-axis. 


\section{Simulation I of photothermally driven bending by using measured top surface temperature}

Time dependence of temperature gradient along the thickness direction was calculated based on the irradiated top surface temperature directly measured with an IR thermography camera.

We input the measured top surface temperature into $T_{0}^{j}$ and computed the temperatures of other meshes $\left(T_{i}^{j}, i=1,2, \ldots, N\right)$ based on Eq. S18 and $\mathrm{S} 21$. The spatial step size $\Delta x$ and the temporal step size $\Delta t$ were set to be $1.932 \mu \mathrm{m}(N=24)$ and $10 \mu \mathrm{s}$, respectively.

According to the Forward Time Centered Space (FTCS) scheme, one of the finite-difference methods (FDM) which calculates the state of a system at a later time ( $j$ ) from the state of the system at the current time $(j-1)$, rate of change of stored energy for the mesh $x_{i}, \Delta q_{i}^{j}$, can be represented as

$$
\Delta q_{i}^{j}=q_{\text {in }}^{j-1}-q_{\text {out }}^{j-1}
$$

where $q_{\text {in }}^{j-1}$ and $q_{\text {out }}^{j-1}$ represent heat flux entering and escaping from the neighboring mesh $\left(x_{i-1}, x_{i+1}\right)$. Given that $T_{i}^{j}>T_{i}^{j-1}$ upon heating, $\Delta q_{i}^{j}$ can be rewritten as

$$
\Delta q_{i}^{j}=\rho C \Delta x \frac{T_{i}^{j}-T_{i}^{j-1}}{\Delta t}
$$

Following Fourier's law, $q_{\text {in }}^{j-1}$ and $q_{\text {out }}^{j-1}$ can be represented as follows:

$$
\begin{aligned}
& q_{\text {in }}^{j-1}=k \frac{T_{i-1}^{j-1}-T_{i}^{j-1}}{\Delta x} \\
& q_{\text {out }}^{j-1}=k \frac{T_{i}^{j-1}-T_{i+1}^{j-1}}{\Delta x}
\end{aligned}
$$

Substituting Eq. S14, S15, S16 into Eq. S13 gives

$$
\rho C \Delta x \frac{T_{i}^{j}-T_{i}^{j-1}}{\Delta t}=k \frac{T_{i-1}^{j-1}-2 T_{i}^{j-1}+T_{i+1}^{j-1}}{\Delta x}
$$

Eq. S17 is rearranged so that the known quantities (i.e. temperature at time $j$-1) are on the right hand site and the unknown quantities (i.e. temperature at time $j$ ) on the left side:

$$
T_{i}^{j}=T_{i}^{j-1}+\alpha \frac{\Delta t}{\Delta x^{2}}\left(T_{i-1}^{j-1}-2 T_{i}^{j-1}+T_{i+1}^{j-1}\right)
$$

This is the governing equation and we can compute the later temperature $(t=j)$ based on the current temperature $(t=j-1)$ without solving any additional equations. 
Next, we specify the initial condition

$$
T_{i}^{0}=T_{a}, 0 \leq i \leq N
$$

where $T_{a}$ is ambient temperature (constant).

For the specific meshes $x_{N}, q_{\text {out }}^{j-1}$ is represented according to Newtonian cooling as

$$
q_{\text {out }}^{j-1}=\gamma_{N}\left(T_{N}^{j-1}-T_{a}\right)
$$

where $\gamma_{N}$ is a numeric constant, giving the following equations (boundary conditions):

$$
T_{N}^{j}=T_{N}^{j-1}+\alpha \frac{\Delta t}{\Delta x^{2}}\left(T_{N}^{j-1}-T_{N-1}^{j-1}\right)-\Gamma_{N}\left(T_{N}^{j-1}-T_{a}\right)
$$

in which

$$
\Gamma_{N} \equiv \frac{\gamma_{N} \Delta t}{\rho C \Delta x}
$$


a

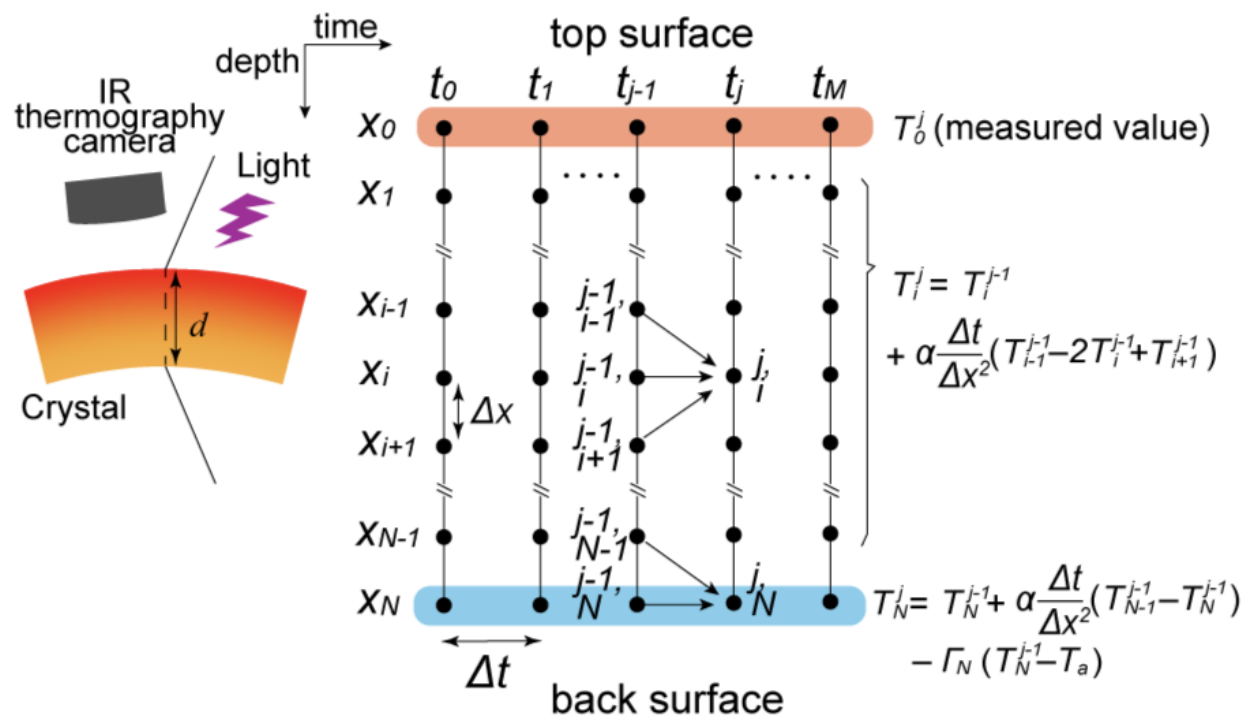

b

C
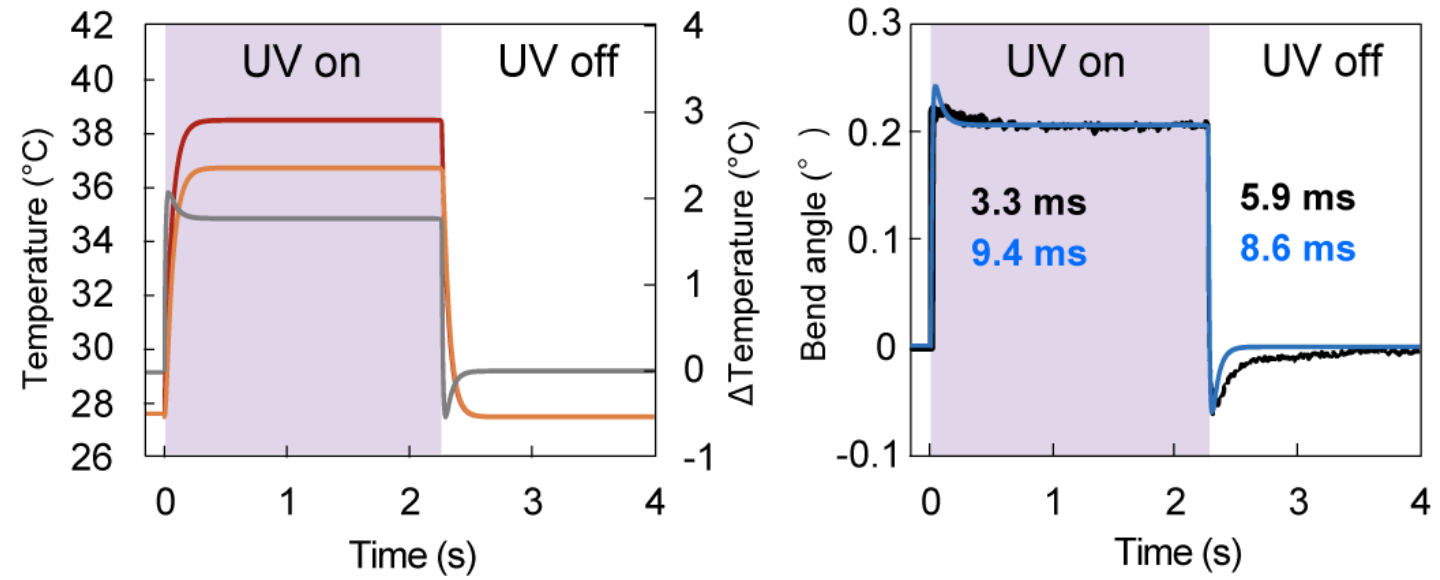

Figure S24. Simulation I of photothermally driven bending of a thick enol-1 crystal $(1524 \times 68.0 \times 48.3$ $\mu \mathrm{m}^{3}$, the same crystal in Figure 4) upon UV laser $\left(375 \mathrm{~nm}, 960 \mathrm{~mW} \mathrm{~cm}{ }^{-2}\right.$, spot diameter $2.6 \mathrm{~mm}$ ) irradiation. $\Gamma_{N}$ was set to be 0.0018 . (a) Schematic illustration for simulation. I. Temperature gradient along the thickness direction was calculated based on the irradiated top surface temperature measured with an IR thermography camera. (b) Time dependence of top surface (red, measured) and back surface (orange, calculated) temperature and temperature difference between two surfaces ( $\Delta T$, gray, calculated). (c) Measured (black) and simulated (blue) bend angle. The numbers in the figures indicate the time constants for bending and straightening. 


\section{Simulation II of photothermally driven bending based on the estimated photothermal energy}

In simulation II, we consider heat generation inside the crystal by the nonradiative deactivation of cis-keto-1* (Figures S18, 19); time dependence of temperature gradient was computed by estimating thermal energy generated through the photothermal effect $\left(q_{g e n}(i)\right)$. Unlike simulation I, we did not use IR thermography to measure the top surface temperature. As in the simulation in Figure S24, the spatial step size $\Delta x$ and the temporal step size $\Delta t$ were set to be $1.932 \mu \mathrm{m}(N=24)$ and $10 \mu \mathrm{s}$, respectively. Eq. S13 can be arranged as

$$
\Delta q_{i}^{j}=q_{\text {in }}^{j-1}-q_{\text {out }}^{j-1}+q_{g e n}(i)
$$

where

$$
q_{g e n}(i)=\frac{Q_{g e n}(i)}{A \Delta t}
$$

Here, $Q_{\text {gen }}(i)$ represents thermal energy generated from a mesh $x_{\mathrm{i}}$ by the photothermal effect and $A$ indicates the surface area of a mesh. (for $Q_{\text {gen }}(i)$, refer to Figure S18, Eq. S3, S4)

Substituting Eq. S14, S15, S16 into Eq. S23 gives

$$
\rho C \Delta x \frac{T_{i}^{j}-T_{i}^{j-1}}{\Delta t}=k \frac{T_{i-1}^{j-1}-2 T_{i}^{j-1}+T_{i+1}^{j-1}}{\Delta x}+q_{g e n}(i)
$$

Eq. S25 is rearranged so that the known quantities (i.e. temperature at time $j$-1) are on the right hand site and the unknown quantities (i.e. temperature at time $j$ ) on the left side:

$$
T_{i}^{j}=T_{i}^{j-1}+\alpha \frac{\Delta t}{\Delta x^{2}}\left(T_{i-1}^{j-1}-2 T_{i}^{j-1}+T_{i+1}^{j-1}\right)+\frac{q_{g e n}(i) \Delta t}{\rho C \Delta x}
$$

This is the governing equation and we can compute the later temperature $(t=j)$ based on the current temperature $(t=j-1)$ without solving any additional equations.

Next, we specify the initial condition

$$
T_{i}^{0}=T_{a}, 0 \leq i \leq N
$$

where $T_{a}$ is ambient temperature (constant).

For the specific meshes $x_{0}$ and $x_{N}, q_{o u t}^{j-1}$ is represented according to Newtonian cooling as

$$
q_{\text {out }}^{j-1}=\gamma_{i}\left(T_{i}^{j-1}-T_{a}\right), i=0, N
$$

where $\gamma_{i}$ is a numeric constant, giving the following equations (boundary conditions):

$$
T_{0}^{j}=T_{0}^{j-1}+\alpha \frac{\Delta t}{\Delta x^{2}}\left(T_{1}^{j-1}-T_{0}^{j-1}\right)-\Gamma_{0}\left(T_{0}^{j-1}-T_{a}\right)+\frac{q_{g e n}(0) \Delta t}{\rho C \Delta x}
$$




$$
T_{N}^{j}=T_{N}^{j-1}+\alpha \frac{\Delta t}{\Delta x^{2}}\left(T_{N}^{j-1}-T_{N-1}^{j-1}\right)-\Gamma_{N}\left(T_{N}^{j-1}-T_{a}\right)+\frac{q_{g e n}(0) \Delta t}{\rho C \Delta x}
$$

in which

$$
\Gamma_{i} \equiv \frac{\gamma_{i} \Delta t}{\rho C \Delta x} i=0, N
$$

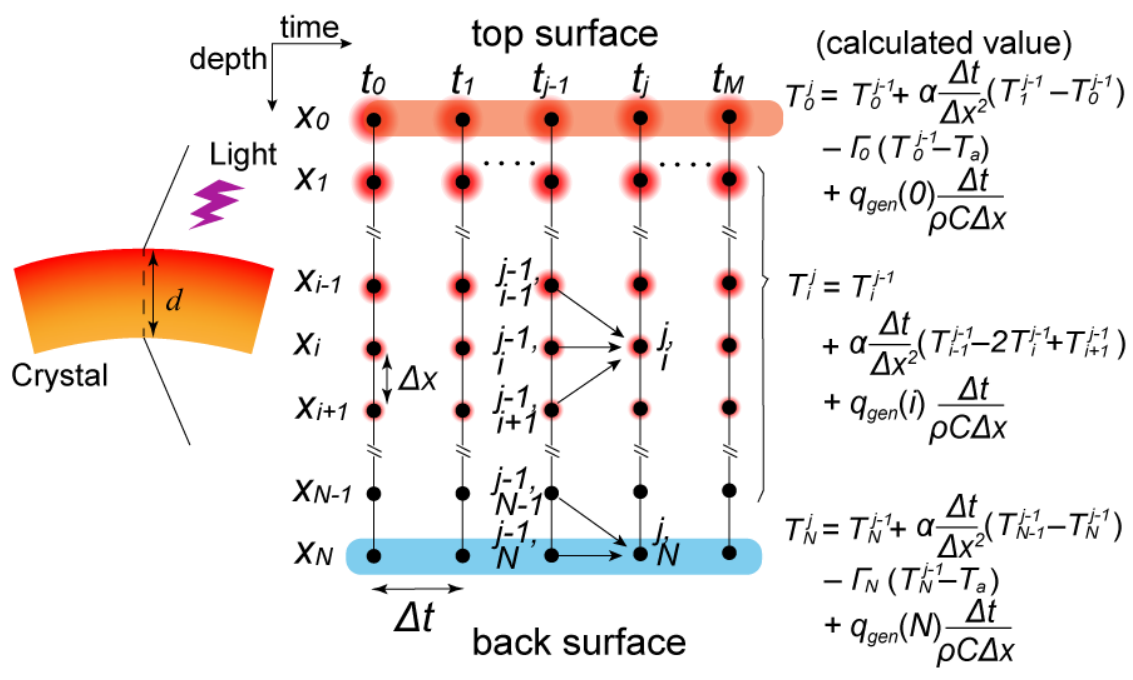

Figure S25. Schematic illustration for simulation II. Temperature gradient along the thickness direction was computed by estimating thermal energy generated by the photothermal effect.

Figure S26a exhibits time dependence of calculated top (red) and back (orange) surface temperature, and temperature difference between the two surfaces ( $\Delta T$, gray) by estimating thermal energy via the nonradiative deactivation process of $c i s-$ keto-1* to cis-keto-1; the maximum temperature of the irradiated top surface was $35.04{ }^{\circ} \mathrm{C}, 3.5{ }^{\circ} \mathrm{C}$ lower than measured value $\left(38.5{ }^{\circ} \mathrm{C}\right)$. The bend angle was, likewise, smaller $\left(0.124^{\circ}\right)$ than the measured value $\left(0.206^{\circ}\right)$ (Figure S26b), suggesting that thermal energy is generated not only from the nonradiative deactivation of excited cis-keto-1*, but also from the nonradiative deactivation of vertically excited FC enol-1* form. Therefore, we estimated thermal energy generated by the photothermal effect $Q_{\text {gen }}$ under the assumption that all the absorbed light energy $(\lambda=375 \mathrm{~nm})$ was converted into heat. Here, $C$ in Eq. S4 can be rewritten as

$$
C=E_{375} \mu A \Delta t \Delta x
$$

where $E_{375}$ is photon energy at $375 \mathrm{~nm}\left(5.297 \times 10^{-19} \mathrm{~J}\right)$. The calculated top surface temperature $\left(38.8{ }^{\circ} \mathrm{C}\right)$ was almost identical to the measure value $\left(38.5{ }^{\circ} \mathrm{C}\right)$ (Figure S26c); likewise the simulated bend angle $\left(0.188^{\circ}\right)$ was comparable to $\left(0.206^{\circ}\right)$ (Figure S26d), supporting the hypothesis that most of the absorbed light energy was converted to the thermal energy in crystal. 

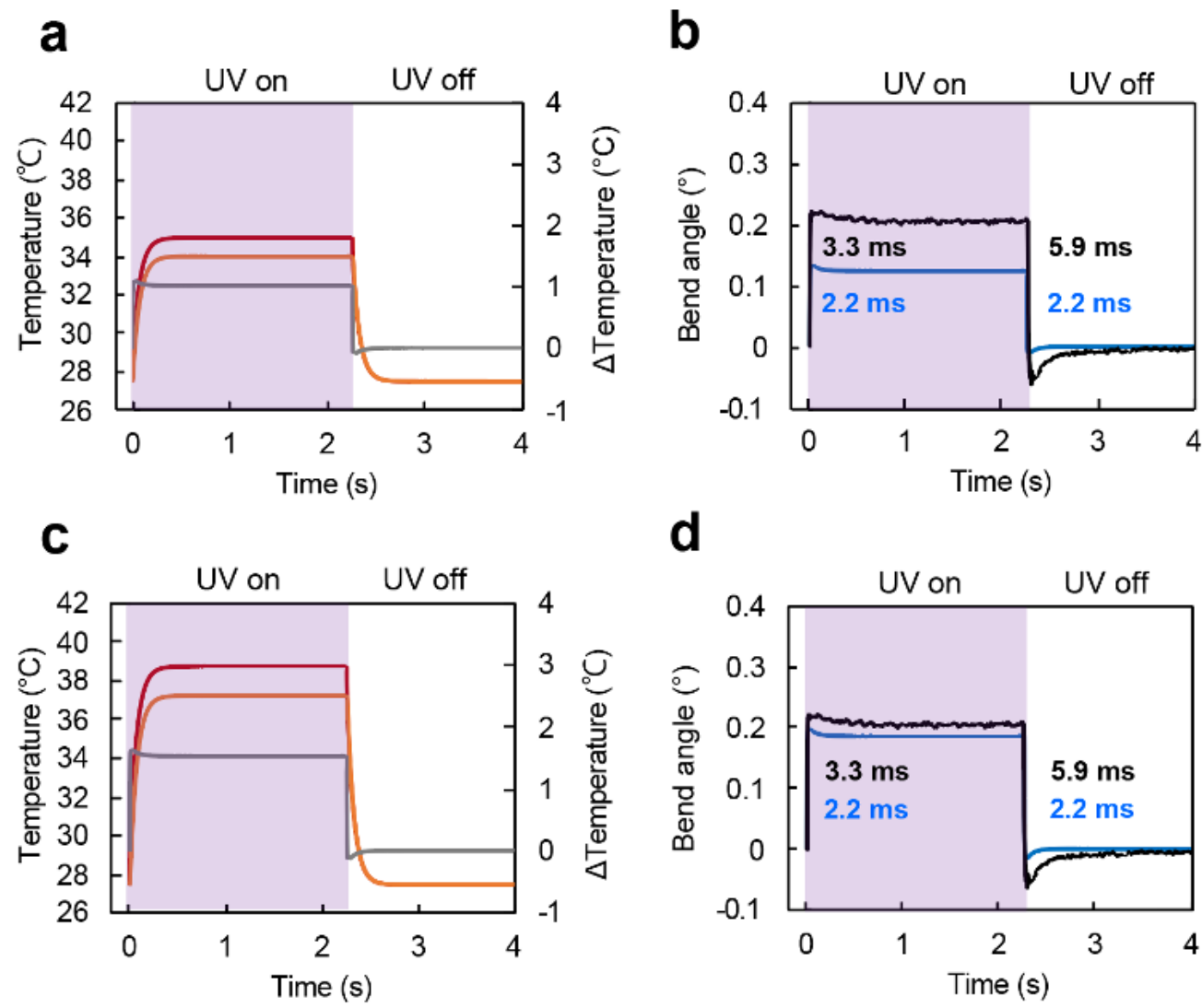

Figure S26. Simulation II of photothermally driven bending of a thick enol-1 crystal $\left(1524 \times 68.0 \times 48.3 \mu \mathrm{m}^{3}\right.$, the same crystal in Figure 4) upon UV laser $\left(375 \mathrm{~nm}, 960 \mathrm{~mW} \mathrm{~cm}{ }^{-2}\right.$, spot diameter $2.6 \mathrm{~mm}$ ) irradiation. $\Gamma_{0}$ and $\Gamma_{N}$ were set to be 0.0020 and 0.0016 . Thermal energy generated by the photothermal effect was estimated $(a, b)$ from the thermal energy generated via cis-keto-1* to cis-keto-1 nonradiative deactivation process (fluorescence wavelength: $561 \mathrm{~nm}$ ), and (c, d) under the assumption that most of the absorbed light energy was converted to the thermal energy in crystal (irradiated light wavelength: $375 \mathrm{~nm}$ ). (a, c) Time dependence of calculated top (red) and back (orange) surface temperature, and temperature difference between the two surfaces ( $\Delta T$, gray). (b. d) Time dependence of measured (black) and simulated (blue) bend angle. The numbers in the figures indicate time constants for bending and straightening. 


\section{List of movies}

Movie S1: bending of the thin plate-like enol-1 crystal $\left(1170 \times 14.5 \times 10.2 \mu^{3}\right)$ by photoisomerization upon UV-LED $\left(365 \mathrm{~nm}, 1300 \mathrm{~mW} \mathrm{~cm}^{-2}\right)$ irradiation from the right for $2 \mathrm{~s}$ and then turning off the UV light (real time) (MP4)

Movie S2: bending of the thick plate-like enol-1 crystal $\left(1520 \times 68.0 \times 48.3 \mu^{3}\right)$ by the photothermal effect upon UV laser $\left(375 \mathrm{~nm}, 960 \mathrm{~mW} \mathrm{~cm}^{-2}\right)$ irradiation from the top for $2.26 \mathrm{~s}$ and then turning off the UV light and simultaneous monitor of surface temperature with an IR thermography camera (real time) (MP4)

Movie S3: bending of the large and thick enol-1 crystal $\left(1700 \times 248 \times 70.4 \mu^{3}\right)$ upon visible laser (488 $\mathrm{nm} 280 \mathrm{~mW} \mathrm{~cm}^{-2}$ ) irradiation from the top for $3 \mathrm{~s}$, and then turning off the light (real time) (MP4)

Movie S4: high-frequency $(500 \mathrm{~Hz})$ bending of the thick plate-like enol-1 crystal $(1912 \times 48.2 \times 35.4$ $\mu^{3}$ ) by pulsed exposure ( $1 \mathrm{~ms} \mathrm{ON}, 1 \mathrm{~ms}$ OFF) of UV laser $\left(375 \mathrm{~nm}, 960 \mathrm{~mW} \mathrm{~cm}^{-2}\right)$ (Slow motion $\times 0.04)(\mathrm{MP} 4)$ 


\section{References}

(1) Koshima, H.; Matsuo, R.; Matsudomi, M.; Uemura, Y.; Shiro, M. Light-Driven Bending Crystals of Salicylidenephenylethylamines in Enantiomeric and Racemate Forms. Cryst. Growth Des. 2013, 13, 4330-4337.

(2) Koshima, H.; Takechi, K.; Uchimoto, H.; Shiro, M.; Hashizume, D. Photomechanical bending of salicylideneaniline crystals. Chem. Commun. 2011, 47, 11423-11425.

(3) Koshima, H.; Ojima, N.; Uchimoto, H. Mechanical Motion of Azobenzene Crystals upon Photoirradiation. J. Am. Chem. Soc. 2009, 131, 6890-6891.

(4) Koshima, H.; Ojima, N. Photomechanical bending of 4-aminoazobenzene crystals. Dyes Pigm. 2012, 92, 798-801.

(5) Taniguchi, T.; Fujisawa, J.; Shiro, M.; Koshima, H.; Asahi, T. Mechanical Motion of Chiral Azobenzene Crystals with Twisting upon Photoirradiation. Chem. Eur. J. 2016, 22, 7950-7958.

(6) Koshima, H.; Nakaya, H.; Uchimoto, H.; Ojima, N. Photomechanical Motion of Furylfulgide Crystals. Chem. Lett. 2012, 41, 107-109.

(7) Koshima, H.; Uchimoto, H.; Taniguchi, T.; Nakamura, J.; Asahi, T.; Asahi, T. Mechanical motion of molecular crystals induced by [4 + 4] photodimerization. CrystEngComm 2016, 18, 7305-7310.

(8) Timoshenko, S. Analysis of Bi-Metal Thermostats. J. Opt. Soc. Am. 1925, 11, 233-255.

(9) Kitagawa, D.; Kobatake, S. Crystal Thickness Dependence of Photoinduced Crystal Bending of 1,2-Bis(2-methyl-5(4-(1-naphthoyloxymethyl)phenyl)-3- thienyl)perfluorocyclopentene. J. Phys. Chem. C 2013, 117, 20887-20892.

(10)Kitagawa, D.; Iwaihara, C.; Nishi, H., Kobatake, S. Quantitative Evaluation of Photoinduced Bending Speed of Diarylethene Crystals, Crystals 2015, 5, 551-561.

(11) Morikawa, J.; Hashimoto, Y. Thermal diffusivity measurement of low-k dielectric thin film by temperature wave analysis. Thermochim. Acta. 2005, 432, 216-221.

(12) Orie, A.; Morikawa, J.; Hashimoto, T. Micro-scale thermal diffusivity measurements of banded spherulites of poly(1-lactic acid) using a thermo-electric micro sensor. Thermochim. Acta. 2012, 532, 148-151.

(13) Morikawa, J.; Hashimoto, T; Kishi, A.; Shinoda, Y.; Ema, K.; Takezoe, H. Critical anomalies in thermal diffusivity of liquid- crystalline terephthal-bis-(4-n-butylaniline). Phys Rev E Stat Nonlin Soft Matter Phys. 2013, 87, 022501.

(14)Ryu, M.; Takezoe, H.; Haba, O.; Yonetake, K.; Morikawa, J. Photo-controllable thermal diffusivity and thermal conductivity driven by the orientation change of nematic liquid crystal with azo- dendrimers. Appl. Phys. Lett. 2015, 107, 221901.

(15)Ryu, M.; Cang, Y.; Wang, Z.; Fytas, G.; Morikawa, J. Temperature-Dependent Thermoelastic Anisotropy of the Phenyl Pyrimidine Liquid Crystal. J. Phys. Chem. C 2019, 123, 17148-17154.

(16) Ryu, M.; Batsale, J. C.; Morikawa, J. Quadrupole modelling of dual lock-in method for the simultaneous measurements of thermal diffusivity and thermal effusivity. Int. J. Heat Mass Transfer 2020, 162, 120337.

(17)Fujisawa, H.; Ryu, M.; Lundgaard, S.; Linklater, D. P.; Ivanova, E. P.; Nishijima, Y.; Juodkazis, S.; Morikawa, J. Direct Measurement of Temperature Diffusivity of Nanocellulose-Doped Biodegradable Composite Films. Micromachines 2020, 11, 738 . 